\title{
Tensiones entre democracia y populismo: una aproximación desde la opinión pública*
}

\section{Tensions between democracy and populism: an approach from the public opinion}

\section{Reynell Badillo Sarmiento ${ }^{\star *}$}

Centro de Pensamiento UNCaribe de la Universidad del Norte (Colombia)

ORCID: 0000-0002-3576-8533

\author{
Alexandra Pérez Jiménez ${ }^{* \star}$ \\ Universidad del Norte (Colombia) \\ ORCID: 0000-0003-2816-742X
}

Fecha de recepción: 10 de noviembre

Fecha de aceptación: 10 de diciembre

\section{ISSN: 2415-2498}

Badillo Sarmiento, R. y Pérez Jiménez, A. (2019). Tensiones entre democracia y populismo: una aproximación desde la opinión pública. Politai: Revista de Ciencia Política, Año 10, segundo semestre, No 19 , pp. 79-108.

DOI: https://doi.org/10.18800/politai.201902.004

\footnotetext{
* Esta es una versión modificada del trabajo de grado de uno de los autores, que puede ser consultado en Badillo Sarmiento (2018).

** Internacionalista de la Universidad del Norte (Barranquilla, Colombia) con énfasis en Ciencia Política y Relaciones Internacionales. Magíster (c) en Estudios Internacionales de la Universidad de los Andes (Bogotá, Colombia). Investigador adscrito al Centro de Pensamiento UNCaribe de la Universidad del Norte.

*** Internacionalista de la Universidad del Norte (Barranquilla, Colombia) con énfasis en Ciencia Política y Relaciones Internacionales. Magíster (c) en Estudios Internacionales de la Universidad de los Andes (Bogotá, Colombia).
} 


\section{RESUMEN}

El populismo ha sido un fenómeno ampliamente estudiado en América Latina. Sin embargo, su análisis ha estado centrado en las implicaciones que tiene para la institucionalidad democrática, lo que ha producido que se desconozcan los efectos que genera en las concepciones democráticas de la población. Esta investigación indaga sobre ¿cómo se ven afectadas las actitudes ciudadanas en relación con el sistema político cuando hay una socavación constante de las instituciones democráticas por parte de políticos populistas? En ese sentido, se analizan los casos de Venezuela, Ecuador y Bolivia a partir de los datos arrojados por el Barómetro de la Américas que permiten examinar el grado de legitimidad democrática en esos países durante los gobiernos de Hugo Chávez, Rafael Correa y Evo Morales, quienes se consideran "políticos con rasgos populistas". Se concluye que, si bien la llegada de políticos populistas en América Latina durante la primera década del milenio obedeció, en parte, a una crisis de legitimidad democrática de los ciudadanos, los proyectos políticos populistas no lograron desarrollar en la población valores democráticos. Por el contrario, la tendencia suele ser que el apoyo al sistema político aumenta considerablemente (confundida usualmente con el apoyo al ejecutivo) mientras la tolerancia política disminuye o se mantiene inestable. Mientras se gestaba una disminución de la calidad institucional de la democracia, en la ciudadanía hubo una transición desde una democracia en riesgo (bajo apoyo al sistema y baja tolerancia política) hacia una estabilidad autoritaria (alto apoyo al sistema y baja tolerancia política).

Palabras clave: populismo, actitudes hacia la democracia, tolerancia política, América Latina, opinión pública. 


\section{Abstract}

Populism has been a phenomenon widely studied in Latin America. However, his analysis has been focused on the implications that it has for democracy. In contrast, little inquiry has been conducted about the unknown effects on the democratic conceptions of the population. This research investigates how citizen attitudes are affected in relation to the political system when there is a constant undermining of democratic institutions by populist politicians? In that sense, the cases of Venezuela, Ecuador and Bolivia are analyzed based on data from the Barometer of the Americas that allow examining the degree of democratic legitimacy in these countries during the governments of Hugo Chavez, Rafael Correa and Evo Morales, who are considered "politicians with populist features". It is concluded that, although the arrival of populist politicians in Latin America during the first decade of the millennium was partly due to a crisis of democratic legitimacy of citizens, it is necessary to take into account that populist political projects failed to develop democratic values in the population. On the contrary, the tendency is usually that support for the political system increases considerably (usually confused with executive support) while political tolerance decreases or remains unstable. While a decrease in the institutional quality of democracy was taking place, the citizenship moved from a democracy at risk (low system support and low political tolerance) to authoritarian stability (high system support and low political tolerance).

Keywords: Populism, attitudes towards democracy, political tolerance, Latin America, political behaviour. 


\section{INTRODUCCIÓN}

La irrupción del siglo XXI en América Latina trajo consigo una nueva ola de políticos cuyos discursos y métodos fueron tildados de populistas. Para algunos autores, aquellos que fueron exitosos, tendieron a controvertir el orden democrático y algunos se transformaron en autoritarismos competitivos (De la Torre, 2007; Roberts, 2007; Levitsky y Roberts, 2011; Levitsky y Loxton, 2013). Este fenómeno ha sido analizado minuciosamente en el continente. Empero, no se ha puesto el mismo empeño en considerar cuál es el efecto que la llegada de estos populismos y el constante cuestionamiento a la institucionalidad ejerce sobre las concepciones democráticas del pueblo ${ }^{1}$. Dicho de otro modo: ¿cómo se ven afectadas las actitudes ciudadanas en relación con el sistema político cuando hay una socavación constante de las instituciones democráticas por parte de políticos populistas? ${ }^{2}$ En este artículo se intenta comprender esta relación a partir de un análisis de los datos del Barómetro de las Américas en Venezuela, Ecuador y Bolivia.

Las principales conclusiones a las que llega este trabajo son que, si bien en el caso boliviano y ecuatoriano la llegada de Evo Morales y Rafael Correa, respectivamente, aportó estabilidad a unos países proclives a la fragilidad política y al cuestionamiento constante del sistema, en los ciudadanos esto no ha significado una transición hacia una democracia estable (o, dicho con mayor rigor, hacia un perfil actitudinal con alto apoyo al sistema y alta tolerancia política), sino que, más bien, ha significado una transición desde democracias en riesgo (bajo apoyo al sistema, baja tolerancia política), hacia una estabilidad autoritaria (alto apoyo al sistema, baja tolerancia política).

El caso venezolano no encaja dentro del anterior esquema por varias razones, entre ellas, el hecho de que no es posible comparar el estado de la legitimidad política antes de la llegada de Hugo Chávez (la primera medición del Barómetro de las Américas es en el 2007) y el hecho de que el país, desde comienzos de la actual década, presenta una crisis económica, social y política que modifica los patrones de comportamiento del pueblo. No obstante, es posible observar dentro de los casi diez años de medición que hay una transición desde una democracia mayoritariamente estable hacia una democracia inestable.

\footnotetext{
${ }^{1}$ Vale la pena resaltar que algunos autores -como Akkerman, Mudde y Zaslove (2013), Schulz et al. (2017), Geurkink, Zaslove, Sluiter y Jacobs (2019) y Castanho, Jungkunz, Helbling y Littvay (2019)- han intentado establecer vínculos entre la literatura sobre populismo y la literatura sobre opinión pública. No obstante, esta aproximación está más preocupada por comprender cómo medir las actitudes populistas en la población que por entender la relación entre orientaciones democráticas y actitudes populistas de los gobernantes. En ese sentido, aunque evidentemente resulta útil para entender las preferencias ciudadanas sobre el populismo, no necesariamente responde a la pregunta de investigación aquí planteada.

${ }^{2}$ Como puede inferirse del hecho de que se señalen las instituciones democráticas como parte importante del sistema político, la relación que se intenta observar en este artículo es entre el populismo y la democracia liberal o institucional (pueden verse los trabajos de Diamond, 1999 y Fuchs y Roller, 2006), lo que, por ejemplo, dejaría por fuera otras visiones sobre la democracia como la "democracia radical", propuesta por Mouffe (1999) y Laclau y Mouffe (2015); "democracia popular", propuesta por Wilde (2017), o la "democracia populista", propuesta por Mair (2002).
} 
Para articular esta respuesta, en primer lugar, se establecerá un marco analítico y se clarificarán los conceptos de populismo y legitimidad democrática. Luego se explorará brevemente el trasegar de la democracia en los países estudiados a partir de la llegada al poder de presidentes con rasgos que pueden considerarse populistas (derivados del marco de análisis), como es el caso de Hugo Chávez Frías, Evo Morales y Rafael Correa, y finalmente se utilizarán los datos del Barómetro de las Américas para establecer la relación entre el estado de la democracia en estos países con proyectos populistas exitosos y el comportamiento de la legitimidad democrática a través de dos variables: el apoyo al sistema político y la tolerancia política, estudiándolos por separado y cruzándolos de forma tal que se puedan obtener los cuatro perfiles actitudinales identificados por el Barómetro de las Américas: democracia estable, democracia inestable, estabilidad autoritaria y democracia en riesgo.

\section{MARCO DE ANÁLISIS}

Definir dos conceptos tan amplios y polisémicos como el populismo y la cultura democrática $^{3}$ resulta realmente complicado; no obstante, tal como lo explica Panizza (2010), "se ha vuelto casi un cliché comenzar a escribir sobre populismo lamentando la claridad acerca del concepto" (p. 9) y esta actitud ha servido para recelar acerca de la utilidad de este como pieza fundamental del análisis político. De esta forma, y a pesar de lo complicado que puede resultar, para evitar ambigüedades sobre el concepto, se hará un repaso sobre los autores clásicos que intentaron ofrecer una definición del populismo y luego se ahondará en la literatura más reciente sobre el fenómeno a fin de establecer algunas características generales sobre las cuales encuadernar a aquellos políticos cuyo discurso o actuaciones puedan categorizarse como populistas. Posteriormente, se repasaré el concepto de cultura democrática con el objetivo de operacionalizar sus componentes.

\subsection{Clarificar el concepto de populismo}

De manera general, el populismo ha sido objeto de indagación por parte de científicos sociales de diversas geografías (Taguieff, 1997; Savarino, 2006; Gidron y Bonikowski, 2013; Gagnon et al., 2018). Si bien es cierto que no se encuentra en la literatura un consenso académico alrededor de lo que significa, a menudo los investigadores se aproximan a este fenómeno a partir de categorías conceptuales o de casos empíricos. Caiani y Graziano (2019) repasan, por un lado, las perspectivas teóricas que se han empleado para comprender el populismo. Este se ha entendido como i) una retórica política; ii) una ideología; iii) un tipo de organización que se sustenta en un liderazgo carismático, o iv) un estilo especial de comunicación usado justamente por este

\footnotetext{
${ }^{3}$ Para efectos de la presente investigación consideraremos de manera indistinta los términos legitimidad democrática, legitimación de la democracia, legitimidad política, actitudes ciudadanas en relación con el sistema político, valores democráticos, cultura democrática y cultura política. Lo anterior en razón de que la mayoría de estos términos son utilizados por el Barómetro de las Américas para englobar las dos partes constituyentes de los perfiles actitudinales conducentes a la estabilidad democrática: apoyo al sistema político y tolerancia política.
} 
tipo de líderes ${ }^{4}$. Por otro lado, los autores distinguen, desde una óptica empírica, movimientos populistas de derecha y de izquierda. Sin embargo, también señalan que se han configurado algunos proyectos que trasgreden el espectro político y decantan en lo que se ha denominado populismos mainstream o híbridos, cuya característica principal es la reivindicación de un paquete de políticas y reclamaciones eclécticas que no se pueden encasillar en una única gama político-ideológica. Además, como resultado de las tendencias actuales y el surgimiento de nuevos movimientos políticos, recientemente los comparativistas han preferido la tipología de populismos inclusivos y excluyentes, basada en la definición de quiénes constituyen "el otro" y quiénes son o representan "el pueblo".

En concreto, los populismos latinoamericanos, especialmente, han llamado la atención de gran parte de los estudios especializados (Cammack, 2000; Leone y Calderón, 2004 y Barros, 2014). Lo anterior se debe, en parte, a lo que algunos han llamado "una tendencia al caudillismo" (Dirmose, 2005), a la reiteración del fenómeno en el subcontinente latinoamericano y también a lo que Fermandois (2015) llama la "diversidad y hasta contradicción de sus características" en esta región. No es falso que el populismo ha asumido los rostros de personajes tan antitéticos entre sí como Alberto Fujimori en Perú y Hugo Chávez en Venezuela. No obstante, reducir los populismos a una situación endógena de América Latina evidencia un reduccionismo poco útil para comprender el fenómeno, más bien, es necesario continuar y profundizar la discusión sobre los elementos que caracterizan un proyecto populista.

A pesar de lo hercúlea que resulta la tarea de enmarcar en una definición los comportamientos de esta diversidad de actores, existen algunos patrones comunes entre ellos que permiten generalizar su actuar. Una de las definiciones que más ha sido utilizada la planteó Mudde (2004), quien afirma que los discursos populistas son detectables porque suelen exudar una fisura entre dos grupos antagónicos y homogéneos: una "élite corrupta" y un "pueblo auténtico" (p. 543). Según esta categorización, el político populista solamente dará por resuelta esta división cuando quienes hagan parte de la escena política expresen la volonté générale, lo cual en la mayoría de los casos quiere decir, cuando quien enarbola la bandera populista llega al poder.

Además de lo anterior, Mudde afirma que el populismo es una Thin-centered Ideology (podría traducirse como ideología ligera o delgada) que, tal como más adelante Mudde y Rovira-Kaltwasser (2013) explicarían, solo captura una pequeña parte de la agenda política y la instrumentaliza y combina a través de diversos discursos (ya sean étnicos, como el de Evo Morales; económicos, como el de Hugo Chávez, o de cualquier

\footnotetext{
${ }^{4}$ El esfuerzo más reciente por clarificar el concepto de populismo proviene de los estudios de comunicación y política que conciben esta clase de proyectos como fenómenos comunicativos. Estas aproximaciones no se concentran en tratar de comprender qué constituye o qué significa populismo, sino en de qué manera se comunican o transmiten los mensajes populistas. Esta visión es valiosa, sobre todo, porque toma en consideración no solo la agencia del "líder carismático", sino también de los ciudadanos (destino de las ideas populistas). De Vreese et al (2018) sugieren otra taxonomía para este fenómeno en el marco del enfoque de comunicación; estos autores plantean grados de populismo: populismo completo; populismo excluyente; populismo anti-elitista; populismo vacío. Para mayor indagación sobre esta perspectiva, ver "Populism as an Expression of Political Communication Content and Style: A New Perspective".
} 
otro tipo). Lo anterior resulta relevante para clarificar que, a partir de la definición de Mudde, no se podría encasillar el populismo a un espectro ideológico: el populismo siempre va de la mano de la profundización de un conjunto de ideas que le dan forma y discurso, pero no es típico de ninguna ideología. Para ejemplificar lo dicho, Mudde y Rovira-Kaltwasser afirman que, mientras en Latinoamérica los populismos han solido emerger bajo la tutela de la izquierda, en Europa ha sido la derecha radical nacionalista la cuna de los principales actores populistas.

Frei y el mismo Rovira Kaltwasser (2008) contribuyen a la definición de ese antagonismo en la sociedad afirmando, a través de Laclau , que el populismo "permite la emergencia de una línea de separación al interior de la sociedad" que separa a dos grupos (que al final son comunidades imaginadas) discrepantes. Desde esta perspectiva, el populismo es un experimento político comandado por un actor (ya sea movimiento social, partido político o líder carismático) que propone un nuevo modelo de sociedad. Esta concepción del populismo resulta relevante porque abre el concepto a movimientos sociales y partidos políticos. Sea cual fuere el caso, el objetivo de un experimento populista será siempre la construcción de un nuevo orden social.

Laclau (2005a), por su parte, plantea que el populismo debe entenderse a partir de tres dimensiones: la existencia de unas demandas particulares, la producción de una frontera antagónica y la presencia de un significante vacío que aglutine la pluralidad. Con respecto al primer punto, el autor plantea que el populismo emerge en medio de una situación social en la cual las demandas se aglutinan alrededor de la idea de que todas permanecen insatisfechas (Laclau, 2005b). Con respecto al segundo elemento, plantea que el proyecto populista debe construir diferencias y, por ende, demarcar un "nosotros" de un "ellos" que permita articular esas demandas (Laclau, 2012). Sobre esto, la diferencia fundamental con otros acercamientos radica en considerar que ese antagonismo se construye y no necesariamente se encuentra determinado por las configuraciones sociales previas (aunque, por supuesto, haya elementos que permitan esa construcción). Finalmente, sobre los significantes vacíos, Laclau (1996) explica que no existe isomorfismo entre significado y significante. El segundo puede exceder su contenido particular y amoldarse a otros que, aunque distintos, encuentran puntos de encadenamiento. En ese sentido, el populismo tiende a aglomerar demandas y descontentos que, si bien no son equivalentes, son en realidad significantes que se "vacían tendencialmente" (Retamozo, 2017, p. 165) para hacerlos coincidir dentro de las reivindicaciones populistas.

Finalmente, Levitsky y Loxton (2013) proponen que el populismo debe ser identificable a través de tres características generales: 1) una amplia movilización de las masas a través de una crítica sostenida contra el establecimiento; 2) los líderes populistas suelen ser outsiders. Es decir, carecen de experiencia política dentro de los partidos políticos tradicionales, y 3) los líderes populistas establecen una conexión personalista con los votantes que desvanece las instituciones y lo asoma como único representante del 
pueblo. Para los autores, cualquiera de estas tres características podría hacer falta en un proyecto populista a excepción de la crítica sostenida al establecimiento político.

Los autores encuentran una paradoja de la lógica populista: por un lado, el populismo es "esencialmente" democrático dado que, a final de cuentas, incluye en la construcción de Estado a grupos marginados durante décadas por el establecimiento político (pobres, minorías étnicas, entre otros). Sin embargo, al mismo tiempo, cuando el populismo goza de un fuerte apoyo popular y se encuentra en el poder, usualmente deriva en regímenes autoritarios competitivos ${ }^{5}$ que desestabilizan la democracia. Así, aunque haya elementos democratizadores en estas lógicas, no queda del todo claro que este fenómeno catalice efectivamente democracias más consolidadas; sin embargo, esta es una discusión abierta que autores como Ulloa (2013), Reano (2014) y Cuñaro y Cuñaro (2017) esbozan con mayor profundidad. Asimismo, es necesario aclarar que el objetivo de este trabajo no es afirmar ni sustentar que el populismo es, per se, una amenaza para la democracia liberal como sistema político. Más bien, lo que se pretende es entender de qué forma se comportan las actitudes ciudadanas ante la llegada al poder de políticos populistas, por lo que se propende por explicar orientaciones democráticas, mas no los cambios en el sistema democrático.

Para este trabajo, el populismo es entendido como una ideología política (ligera, en los términos de Mudde y Rovira-Kaltwasser) con tres dimensiones particulares. En primer lugar, hay actitudes antielitistas en quienes enarbolan estas banderas (es decir, se señala particularmente la existencia de unas élites gobernantes a las cuales se les rechaza tajantemente). En segundo lugar, estas actitudes antielitistas vienen acompañadas de la idea de que la soberanía popular es la que debería establecerse (por tanto, hay un rechazo explícito al establecimiento, para utilizar los términos de Levitsky y Loxton, y una propensión por dejar el poder en manos del "pueblo") y, finalmente, se refuerza la idea de que ese pueblo que se señala es homogéneo y virtuoso en sí mismo, como puede ser evidenciado en Wirth et al (2016). Así, aunque en principio se parte de la definición de Mudde y Rovira-Kaltwasser (2013), también se incorporan elementos de otros autores, como los mencionados, y el análisis multidimensional de Schulz et al (2017).

\subsection{Hacia una definición de cultura democrática}

El Proyecto de Opinión Pública de América Latina (LAPOP, por sus siglas en inglés), desarrollador del Barómetro de las Américas, "define la legitimidad política en

\footnotetext{
${ }^{5}$ Los regímenes autoritarios competitivos son un tipo de régimen híbrido en el que "las instituciones democráticas formales son ampliamente vistas como medios principales para obtener y ejercer la autoridad política" (Levitsky y Way, 2010, p. 161). Para los autores, en estos regímenes el gobierno de turno viola frecuentemente los criterios y normas en aras de crear un campo de juego desigual entre gobierno y oposición. "Aunque se den con regularidad elecciones sin fraude, los funcionarios abusan constantemente de los recursos del Estado, no ofrecen a la oposición un cubrimiento adecuado de los medios, persiguen a los candidatos de la oposición y a sus seguidores y, en algunos casos, manipulan los resultados de las elecciones" (p. 162). Según los autores, a pesar de la dificultad de la oposición para enfrentarse al gobierno, existen cuatro arenas en las cuales la primera puede enfrentarse y debilitar al segundo: la arena electoral, la arena legislativa, la arena judicial y los medios de comunicación. En todos estos, el gobierno intentará reprimir las posibilidades de influencia opositora, pero eventualmente podrá perder posiciones y hasta el poder.
} 
términos de apoyo ciudadano al sistema político" (Carlin, Love y Singer, 2015, p. 93) y considera que este apoyo al sistema cuenta con dos dimensiones fundamentales: el apoyo difuso y el apoyo específico ${ }^{6}$. Como Carlin (2018) explica, los datos recogidos por el Barómetro de las Américas solo capturan la dimensión difusa del apoyo que, para Booth y Seligson (2009), es fundamental en aras de evaluar la estabilidad democrática. De la misma forma, dado que el análisis del presente trabajo se basa en los datos recogidos por el Barómetro de las Américas, se hará énfasis en la dimensión difusa de apoyo a la democracia sin que esto impida la utilización de la dimensión específica de apoyo para ofrecer explicaciones en caso de ser necesarias.

Además de este apoyo difuso al sistema, la otra dimensión central para analizar la estabilidad democrática es la tolerancia política, entendida como "el respeto de los ciudadanos hacia los derechos políticos de otros, especialmente aquellos con los que difiere" (Carlin, Love y Singer, 2015, p. 106). Esta segunda dimensión de la estabilidad democrática puede observarse a la luz del trabajo de Gibson (2011), en el que el autor explica que, en un sistema democrático, todas las ideas deben tener las mismas posibilidades de acceder al Marketplace of ideas y que una intolerancia política expandida entre las masas puede ocasionar consecuencias políticas importantes para la estabilidad democrática. Asimismo, puede observarse la relación entre tolerancia política y democracia en trabajos como los de Dahl (1989), Gibson (1996), Finkel, Sigelman y Humphries (1999) y Finkel (2002).

De esta forma, el apoyo al sistema y la tolerancia política se convierten en las dos variables a analizar durante la presente investigación. La primera de ellas podría considerarse de tipo vertical debido a que alude a la relación entre el pueblo y las instituciones. Asimismo, una alta proporción de ciudadanos que apoyan el sistema democrático puede producir gobernabilidad y estabilidad (García, Rodríguez, Seligson y Zechmeister, 2015). Por su parte, la segunda variable tiene un carácter más horizontal al tratarse de interacciones entre ciudadanos con discursos políticos. Una sociedad que puntúa alto en tolerancia política puede considerarse democrática, pero no necesariamente estable. Al transar estas dos variables, se puede construir una tipología de los perfiles actitudinales de los ciudadanos que está condensada en la Figura 1.

Figura 1. Relación entre apoyo al sistema y tolerancia política: perfiles actitudinales de los ciudadanos

\begin{tabular}{|lcl|}
\hline & Alta tolerancia & Baja tolerancia \\
\hline Alto apoyo al sistema & Democracia estable & Estabilidad autoritaria \\
\hline Bajo apoyo al sistema & Democracia inestable & Democracia en riesgo \\
\hline
\end{tabular}

Fuente: Elaboración propia a partir de Carlin, Love y Singer (2015)

\footnotetext{
${ }^{6}$ Esta distinción es tomada de Easton (1975), quien define el apoyo específico como "la satisfacción que los miembros de un sistema sienten con el desempeño de las autoridades políticas" (p. 437) y el apoyo difuso como las evaluaciones que los miembros de un sistema hacen de un objeto político por lo que representa y no por la manera en la que se comporta. Dicho de otro modo, el apoyo difuso es un "reservorio de actitudes favorables (...) que ayuda a los miembros a aceptar o tolerar outputs a los cuales estos se oponen" (p. 444).
} 
Este modelo propone que, en sociedades altamente tolerantes y con ciudadanos que apoyen al sistema de manera mayoritaria, habrá una democracia estable y con pocos riesgos de deterioro. En sociedades en las que las personas apoyan el sistema político, pero son intolerantes frente a sus opositores políticos, se darán condiciones propicias para que el sistema transite hacia el autoritarismo. El tercer escenario es en el que existe una tolerancia política generalizada, pero un bajo apoyo al sistema; aquí, aunque se pueda presentar inestabilidad política, se espera el sostenimiento de la democracia, aunque en condiciones precarias. Por último, en escenarios en los que ni la tolerancia política ni el apoyo al sistema cuentan con apoyo entre la población, las instituciones democracias se encuentran en grave riesgo de colapsar.

Para operacionalizar la variable de apoyo al sistema, LAPOP creó un índice a partir de los promedios de respuestas de los ciudadanos de cada país de la medición a cinco preguntas realizadas durante la encuesta del Barómetro de las Américas ${ }^{7}$. Este índice es recodificado en una escala de 0 a 100 en donde 0 representa muy bajo apoyo al sistema político y 100 representa apoyo muy alto.

Por su parte, la tolerancia política es medida a través de cuatro preguntas realizadas durante la encuesta ya mencionada ${ }^{8}$. Luego, estas preguntas son recodificadas en una variable que va de 0 a 100, en donde 0 implica nula tolerancia política y 100 el nivel más alto de tolerancia política.

Finalmente, ambas variables (apoyo al sistema y tolerancia política) son combinadas en aras de identificar las actitudes que, en teoría, favorecen la democracia. De acuerdo con los resultados, aquellos individuos que obtienen puntajes mayores a 50 poseen actitudes que conducen a una democracia estable y aquellos cuyo puntaje es inferior a 50 son considerados ciudadanos con actitudes que ponen a la democracia en riesgo. Luego, si existe alta tolerancia política, pero bajo apoyo al sistema, se considera que la democracia es inestable, y si la tendencia es la contraria (alto apoyo al sistema en contextos de baja tolerancia política), entonces existe una estabilidad autoritaria.

La legitimidad democrática en este texto será entendida entonces como el conjunto de orientaciones que los ciudadanos expresan hacia el sistema político. Por razones metodológicas, esta solo será medida a través de dos variables: el apoyo difuso al sistema y la tolerancia política. La primera de estas, una variable de carácter vertical, y la segunda de carácter horizontal. Altos niveles de legitimidad democrática en una

\footnotetext{
${ }^{7}$ Estas son: 1) ¿Hasta qué punto cree usted que los tribunales de justicia de (país) garantizan un juicio justo? 2) ¿Hasta qué punto tiene usted respeto por las instituciones políticas de (país)? 3) ¿Hasta qué punto cree usted que los derechos básicos del ciudadano están bien protegidos por el sistema político de (país)? 4) ¿Hasta qué punto se siente usted orgulloso de vivir bajo el sistema político de (país)? 5) ¿Hasta qué punto piensa usted que se debe apoyar al sistema político de (país)?

${ }^{8}$ Estas preguntas son: 1) Hay personas que siempre hablan mal de la forma del gobierno de (país), no solo del gobierno de turno, sino del sistema de gobierno, ¿con qué firmeza aprueba o desaprueba usted el derecho a votar de esas personas? 2) ¿con qué firmeza aprueba o desaprueba usted que estas personas puedan llevar a cabo manifestaciones pacíficas con el propósito de expresar sus puntos de vista? 3) Siempre pensando en los que hablan mal de la forma de gobierno de (país). ¿Con qué firmeza aprueba o desaprueba usted que estas personas puedan postularse para cargos públicos? 4) ¿Con qué firmeza aprueba o desaprueba usted que estas personas salgan en televisión para dar un discurso?
} 
sociedad permiten proyectar cierto nivel de estabilidad democrática. Por el contrario, bajos niveles de legitimidad democrática, expresan cierto grado de riesgo para el sistema democrático. Cuando las variables en juego se encuentran en posiciones opuestas, se puede percibir una democracia inestable o la existencia de una estabilidad autoritaria.

La medición de actitudes ciudadanas a través de los índices de apoyo al sistema y tolerancia política presenta limitaciones técnicas. Autores como Fuks, Avila, Quaresma y Felizardo (2016) afirman que, por su parte, el apoyo al sistema en América Latina se ha medido en muy pocas encuestas unificadas y, además, cuando se ha hecho (como en el Latinobarómetro), ha tendido a hacerse a través de una única pregunta relacionada con el apoyo o la preferencia del encuestado por la democracia, lo que no necesariamente evidencia actitudes que pueden no ser conscientemente asociadas con la democracia. En ese sentido, Carlin y Singer (2011) proponen mediciones "multidimensionales" que sean capaces de abordar diversas aristas del apoyo al sistema político. Dado que el índice del Barómetro de las Américas incluye cinco preguntas distintas relacionadas con esa categoría y que estas hacen parte del núcleo básico de preguntas regionales, los autores consideran útil utilizarlo como variable comparativa.

Con respecto a la segunda variable por analizar, la tolerancia política, hay menos información que sobre la anterior (puesto que solo el Barómetro de las Américas hace una medición de este tipo) y más controversia sobre su aplicación. Las preguntas para construir este índice pueden llevar a que aquellos que se consideran críticos del gobierno de turno alteren la medición (puesto que difícilmente estos van a afirmar estar en contra de sus propios derechos políticos). En ese sentido, han sido propuestas otras estrategias como la del "least-liked group", en la que se plantea que, antes de preguntarle al entrevistado por los derechos políticos de la oposición de forma general, se le pida manifestar su aversión/gusto por determinados grupos humanos o políticos $\mathrm{y}$, posteriormente, preguntar particularmente por los derechos del conglomerado con peor puntuación (Ribeiro y Borba, 2017). No obstante, esta estrategia no ha sido aplicada para los países en comparación, por lo que solo se podrá observar el índice de tolerancia política tradicional.

En ese sentido, se decide utilizar el Barómetro de las Américas por la amplitud de sus muestras, porque hay preguntas dentro de un núcleo común que son realizadas en varios países durante periodos similares y porque es una de las pocas encuestas que intenta medir la tolerancia política y elabora un índice multidimensional de apoyo al sistema político. Pese a esto, así como se hace evidente más adelante, los autores son conscientes de sus límites en lo referente al estudio de la tolerancia política y a los años de la medición.

\section{Trayectorias deMOCRÁticas de Venezuela, Bolivia y ECUADOR}

En diciembre de 1998 fue elegido Hugo Chávez Frías como presidente constitucional de Venezuela. Estas elecciones estuvieron marcadas por la crisis económica que había estallado desde finales de los 70 y todavía aquejaba al aparato productivo del país. Hugo Chávez, sobreseído por el presidente Caldera luego de un 
fallido golpe de Estado en 1992, abogó al salir de la cárcel por abstenerse de votar alegando que el sistema en su conjunto había fracasado y esa era una forma de manifestarse y denostarlo (Ponce, 2014). Aun así, antes de recibir el nuevo milenio, ya Venezuela había votado por una Asamblea Nacional Constituyente y una nueva constitución que fundó la República Bolivariana de Venezuela. Años después, Chávez Frías sería acusado de debilitar a la oposición, modificar la ley para beneficiarse y destruir las instituciones democráticas (Almonte y Crespo, 2008). La nueva constitución venezolana alargó el periodo presidencial a seis años y estableció la posibilidad de reelección inmediata por una sola vez. Asimismo, la Asamblea Nacional, ahora representante del poder legislativo, vio reducidas sus funciones y el presidente ostentó, desde la promulgación de la nueva carta fundacional, la libertad para elegir a los altos mandos de las fuerzas militares sin intervención de ningún otro órgano del Estado (Márquez, 2004).

En el 2005 Bolivia eligió por primera vez en su historia a un nacional de origen indígena como presidente del Estado. Evo Morales había sido activista por los derechos de los indígenas y campesinos desde 1980 y en 1997 había inaugurado su carrera política al resultar elegido diputado por Cochabamba, misma región que protagonizó en el 2000 una de las mayores crisis en América Latina dados los exagerados incrementos en las tarifas de agua luego de que el exdictador Hugo Banzer privatizara el servicio. En el 2006, año en el que Evo se posesionó, el presidente boliviano convocó a una Asamblea Nacional Constituyente que redactó la constitución que entró en vigor en el 2009, a través de la que se fundó el Estado Plurinacional de Bolivia. Morales ha sido acusado de instrumentalizar el discurso de la autonomía indígena para consolidar un autoritarismo e intentar permanecer en el poder indefinidamente (García, 2012; Segal, 2013).

El 2 de julio del 2006, apenas 5 meses después de que Morales se posesionara como presidente de Bolivia, se efectuaron los comicios para elegir a los miembros de la Asamblea Nacional Constituyente. El partido oficialista, Movimiento al Socialismo (MAS), obtuvo la mayoría absoluta con 137 de los 255 escaños y se alzó como la fuerza política más importante del país. No obstante, esto no le alcanzó para asirse con la mayoría calificada de 2/3 que establecía la Ley Especial de Convocatoria a la Asamblea Nacional Constituyente en su artículo 25 para la aprobación del texto constitucional.

A pesar de la aparente victoria de la oposición y la composición pluralista de la Asamblea, el MAS intentó modificar las reglas para que las decisiones fueran tomadas por mayoría absoluta, favoreciendo al partido del presidente Morales. El mismo vicepresidente Álvaro García Linera (citado en Franchini, 2007) se expresó, en referencia a la negativa de la oposición para aceptar la postura del MAS, de la siguiente manera:

Tienen que aprender esos partidos minoritarios que la ley de la democracia es la ley de la mayoría... Las minorías tienen derecho, están ahí, nos sentimos muy contentos, pero las mayorías no van a moverse al compás de pequeñas minorías transitorias y chantajistas ( $\mathrm{p}$. 7).

Desde este momento, Morales tendría fuertes enfrentamientos con otros órganos del poder público. En el 2007, enjuició a la mayoría de los miembros del Tribunal 
Constitucional posterior a un fallo contrario a los intereses del MAS. Dos años después, Silvia Salame renunció al Tribunal Constitucional luego de varios meses siendo la única magistrada (Fundación Konrad Adenauer y Polilat, 2009; Mancini, 2014). En los años siguientes hubo tensiones con los medios de comunicación debido a una controvertida ley de telecomunicaciones en la que se repartían las licencias entre el Estado (33\%), las organizaciones comunitarias (17\%), las organizaciones indígenas (17\%) y el sector privado $(33 \%)$ y se autorizaba al Estado a interceptar las comunicaciones entre los ciudadanos en momentos de "crisis nacional". En el 2014, Evo Morales es reelegido avalado por el Tribunal Constitucional, a pesar de que la Constitución y la Ley Electoral prohibían esta figura.

El 21 de febrero del 2016, Morales perdió su primera elección desde que llegó al poder, cuando el referendo constitucional que pretendía validar una nueva reelección fue derrotado. Si bien la aceptación del gobierno de los resultados del referendo fue entendida como un gesto democrático y valioso para la participación política en Bolivia, en noviembre del 2017 el Tribunal Constitucional Plurinacional de Bolivia desconoció el mandato popular y autorizó a Evo Morales para ser reelegido indefinidamente. En octubre de 2019, el Tribunal Electoral de Bolivia proclamó ganador a Morales en los últimos comicios celebrados en este país. Lo anterior sugiere que el presidente boliviano podría haber estado 19 años de manera ininterrumpida en el poder, lo cual no se concretó debido a su renuncia en noviembre del mismo año ${ }^{9}$.

Con respecto a Ecuador, en el 2006, durante la campaña presidencial, Rafael Correa, un economista sin mayor bagaje político, propuso convocar a una Asamblea Nacional Constituyente, desistió de presentar candidatos a las elecciones parlamentarias y les hablaba a los indígenas de su país en quechua. Prometía una "revolución ciudadana" que modificaría el orden social, político y económico existente. Correa resulta elegido presidente y un año después de su posesión, la República del Ecuador adoptaría una nueva constitución redactada por una Asamblea Nacional Constituyente mayoritariamente oficialista. La administración de Correa puso fin a una decena de gobiernos diferentes que ejercieron el poder durante una década. Además de la reforma al sistema político ecuatoriano, la herencia correísta incorporó una visión económica opuesta al pensamiento liberal capitalista, esto es una propuesta enmarcada en la noción de la economía de solidaridad (Tibocha y Jaramillo Jassir, 2008). Diez años después, luego de enarbolar las banderas del Socialismo del Buen Vivir (Luna, 2014), Rafael Correa dejó el gobierno perseguido por acusaciones de corrupción y de cercenar las libertades civiles bajo los ciernes de un gran momento económico (De la Torre, 2010; Basabe y Martínez, 2014).

\footnotetext{
${ }^{9}$ Debido a denuncias de fraude realizadas por la oposición, posteriormente ratificadas por la Organización de Estados Americanos (OEA), Bolivia enfrentó una sucesión de fuertes manifestaciones y protestas ciudadanas que llevaron a la convocatoria de nuevas elecciones por parte del presidente Morales. El descontento de la población no cesó y el primer mandatario perdió apoyo sindical y político. Finalmente, en noviembre de 2019, Evo Morales anunció su renuncia a la presidencia de su país y, posteriormente, Jeanine Áñez, entonces miembro del legislativo, asume la presidencia provisionalmente.
} 
Figura 2. Índice de Desarrollo Democrático para Venezuela, Bolivia y Ecuador (2002-2016) ${ }^{10}$

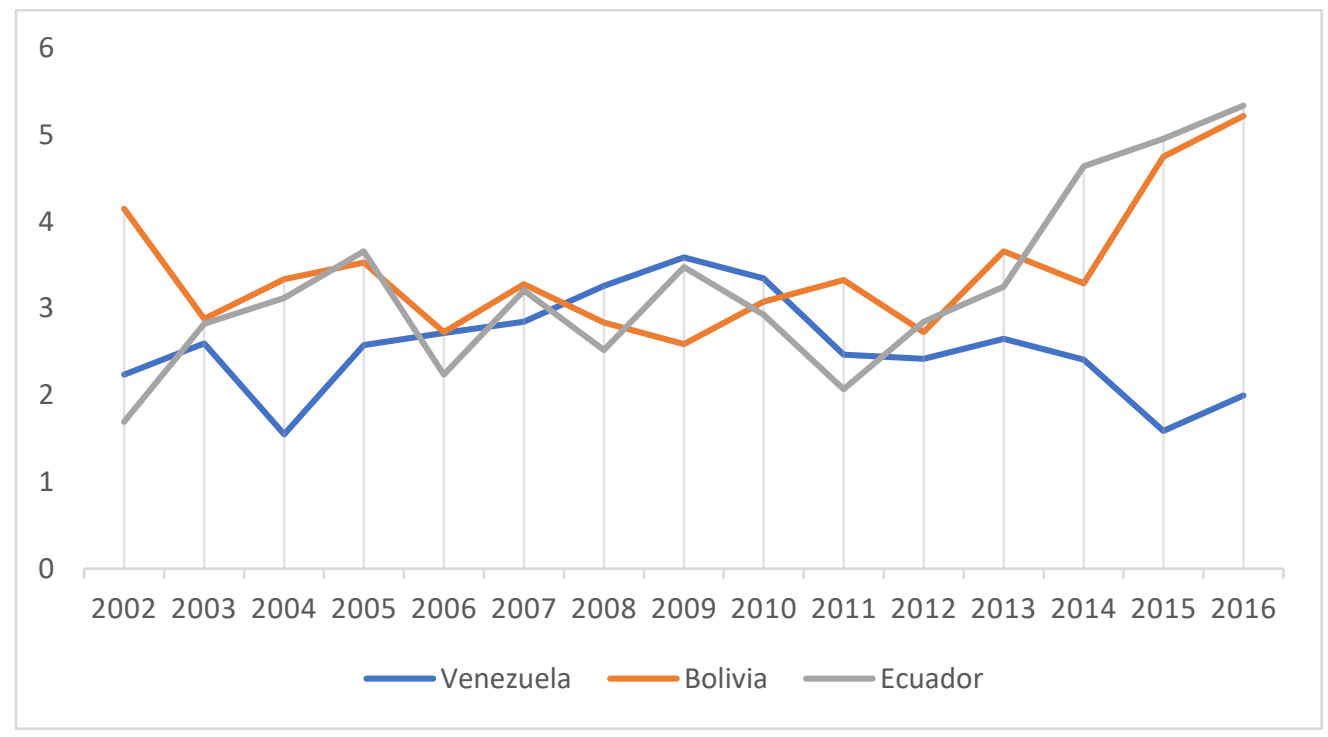

Fuente: Elaboración propia a partir de los datos del Índice de Desarrollo Democrático elaborado por la Fundación Konrad Adenauer y Politat. Disponible en: http://idd-lat.org/

En la figura 2 puede observarse que, en términos generales, la llegada al poder de Rafael Correa y Evo Morales en Ecuador y Bolivia permitió una tendencia al alza en el Índice de Desarrollo Democrático (IDD). Si bien este no fue sostenido y estable, Ecuador pasó de puntuar 2,24 en el 2006 (año de la llegada de Correa) a 5,34 diez años después. Bolivia, por su parte, este mismo año puntuó 2,73, mientras que en el 2016 alcanzó 5,22 puntos. Venezuela presenta, desde el 2009, una tendencia a la baja que la llevó a obtener solo 2 puntos en la medición del 2016. No obstante, es menester resaltar que este país nunca obtuvo altos resultados y, de hecho, entre el 2002 y el 2014, ocupó por 8 años los tres últimos lugares del ranking —en dos ocasiones fue el país con peor desempeño (18), por dos años fue penúltimo (17) y en cuatro ocasiones se ubicó antepenúltimo (16).

\footnotetext{
${ }^{10}$ El IDD está compuesto por cuatro dimensiones particulares: I) Democracia de los ciudadanos - Respeto de las libertades civiles y derechos políticos. II) Democracia de las instituciones - Calidad institucional y eficiencia del sistema político. III) Democracia social - Poder efectivo para gobernar generando mejores condiciones de desarrollo social y humano. IV) Democracia económica - Poder efectivo para gobernar generando mejores condiciones de desarrollo económico. Para obtener más información sobre la construcción de cada índice puede observarse a IDD-MEX (2018). Se incluyen datos solo hasta el 2016 dado que, desde este año, la medición en algunos países no se ha llevado a cabo. Asimismo, las tendencias evidencias en el IDD coinciden con otros índices democráticos tales como el Índice del Estado de Derecho (Rule of Law Index) del World Justice Project o el Índice de Democracia (Democracy Index) elaborado por The Economist.
} 
Figura 3. Dimensión "democracia de los ciudadanos" del Índice de Desarrollo Democrático para Venezuela, Bolivia y Ecuador (2005-2016)

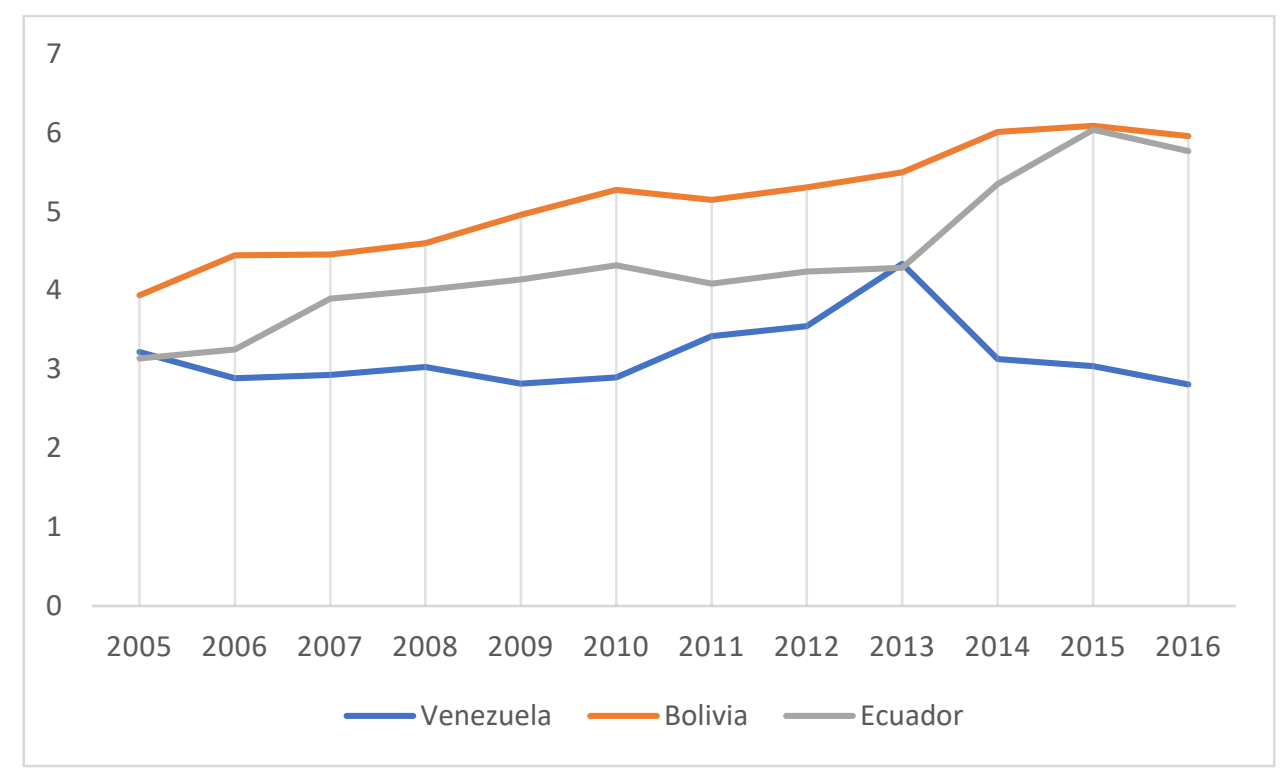

Fuente: Elaboración propia a partir de los datos del Índice de Desarrollo Democrático elaborado por la Fundación Konrad Adenauer y Politat. Disponible en: http://idd-lat.org/

Por el contrario, si se desagregan los datos del IDD en dos de sus dimensiones (democracia de los ciudadanos ${ }^{11}$ y democracia de las instituciones ${ }^{12}$ ), puede observarse que, mientras en la primera se observan avances importantes en los tres países, al menos hasta el 2013, cuando se deteriora en Venezuela, en la segunda hay una marcada inestabilidad y, de hecho, la tendencia ha sido a reducir el puntaje en esta dimensión. Venezuela pasó de 3,22 en el 2005 a 1,51 (el puntaje más bajo de la región) en el 2016. En este mismo periodo, Bolivia estuvo en 4,73 y 4,77. Sin embargo, durante el resto de años el país no superó los 4 puntos y en el 2014 tuvo su puntuación más baja $(2,3)$. Ecuador pasó de 5,76 a 3,18 y en el 2011 estuvo en 1,56, cercano al último puntaje de Venezuela. Esto permite observar un elemento de la "paradoja del populismo" mencionado previamente: mientras hay una suerte de poder democratizador entre los derechos ciudadanos y la posibilidad de más personas de acceder a estos, sigue presentándose una brecha con respecto al mantenimiento institucional del sistema.

\footnotetext{
${ }^{11}$ Esta dimensión captura las condiciones reales que tienen los ciudadanos para ejercer sus derechos y libertades civiles.

${ }^{12}$ Esta dimensión captura la calidad de las instituciones y la independencia que tienen para actuar de cara al ejecutivo.
} 
Figura 4. Dimensión “democracia de las instituciones" del Índice de Desarrollo Democrático para Venezuela, Bolivia y Ecuador (2005-2016)

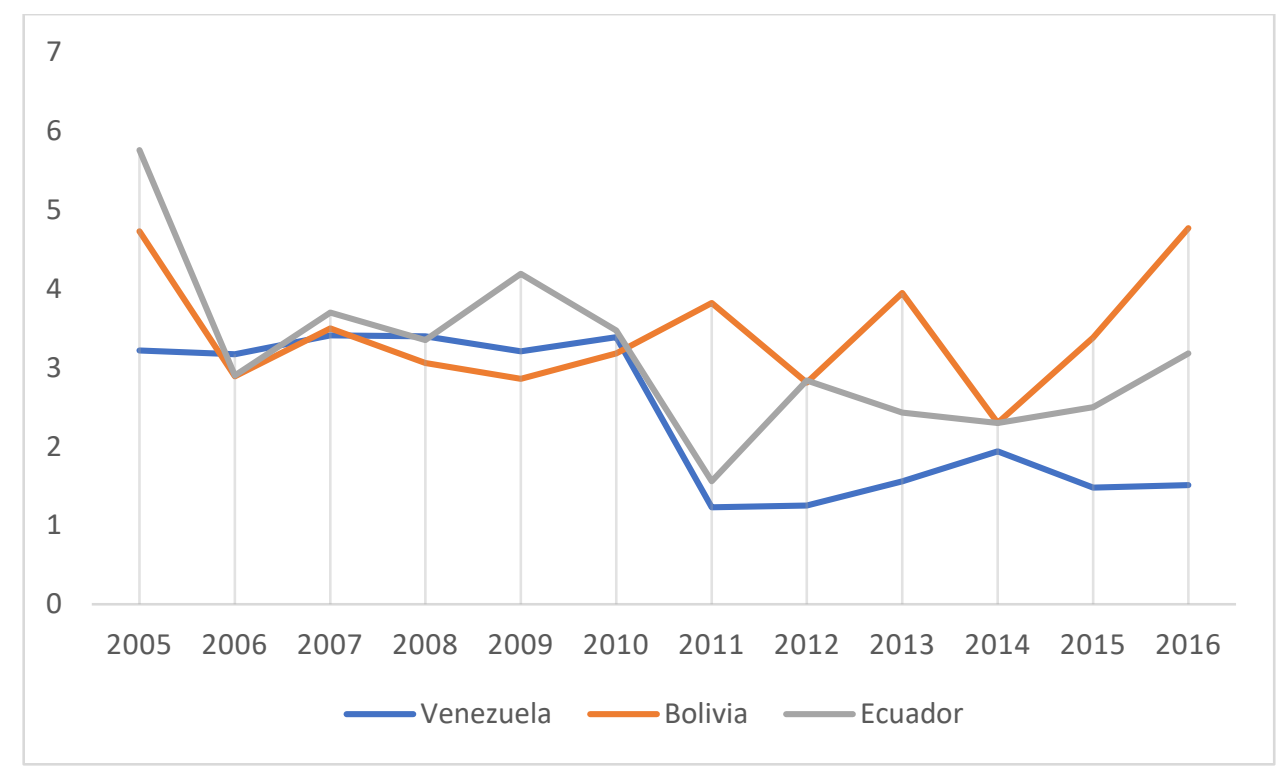

Fuente: Elaboración propia a partir de los datos del Índice de Desarrollo Democrático elaborado por la Fundación Konrad Adenauer y Politat. Disponible en: http://idd-lat.org/

\section{Legitimidad democrática en Venezuela, Bolivia y ECUAdor: Apoyo al SISTEMA POLÍTICO}

En la figura 5 puede observarse la variación en el índice de apoyo al sistema político en los tres países estudiados. Para el caso venezolano, hasta el 2014 se presentó un nivel bastante alto tanto en términos generales (solía estar cerca o muy cerca de la mitad) como a nivel comparativo entre los países de la región. Hawkins, Patch y Anguiano (2008) explican esto a través de la asociación de las respuestas con la filiación partidista de los encuestados. Así, por ejemplo, mientras el 73,7\% de quienes se identificaron como partidarios del presidente Chávez respondieron que se sentían orgullosos del sistema político del país, apenas el 24,6\% de quienes no coincidían con el líder venezolano lo expresaron así. Esta proporción permanece casi intacta cuando se analiza la puntuación general en el apoyo al sistema político: mientras el 74\% de quienes se asumieron como seguidores de Chávez puntuaron por encima de la media en esta sección, apenas el $27 \%$ de quienes se consideraban opositores del presidente obtuvo resultados similares.

Por su parte, en Bolivia se puede observar una tendencia estable, pero con niveles bajos durante los años previos a Morales (1998-2004). La inestabilidad política del país y la crisis de representatividad de los partidos políticos tradicionales y las instituciones explican este desempeño (Seligson et al., 2007). El cambio en la tendencia a partir del 2006 es evidente y, aunque se pueden observar ligeras variaciones, como entre el 2008 y el 2010, cuando aumentó casi 4 puntos la medición, y entre el 2010 y el 2012, cuando este aumento cae precipitadamente, la puntuación del 2016 refleja en cierta medida la 
tendencia de esa década en el país. Dicho de forma más clara, la llegada de Morales coincide con un aumento de casi 6 puntos porcentuales en el promedio de este indicador.

Durante algunos años de la medición, este buen desempeño le valió a Bolivia para ubicarse por encima de Brasil y Estados Unidos en esa variable. Moreno, Córdova, Schwarz, Vargas y Villarroel (2010) demuestran que la evaluación del desempeño económico del gobierno es el factor que más influye en el apoyo al sistema en este país. Es decir, para los bolivianos será muy importante la percepción que tengan del comportamiento de la economía de su país a la hora de expresar su posición sobre el apoyo al sistema político. 2012 fue el año de peor desempeño de esta categoría durante la presidencia de Evo Morales. Ese año, Bolivia se ubicó 20 de 26 países medidos en la región. La reducción del índice fue de cerca de 6 puntos, casi los mismos que incrementó en el 2006 con la llegada de Morales.

Mientras que la aprobación del trabajo del presidente incide positivamente en la variable de apoyo al sistema, las personas que se autoidentificaron como indígenas mostraron menor adhesión al sistema político que los demás. Esto último puede tener explicación en la actitud represiva del gobierno de Morales frente a la población indígena que protestó por la construcción de una carretera en el TIPNIS (Territorio indígena y parque nacional Isiboro-Sécure) (Ciudadanía y LAPOP, 2012). Sin embargo, el hecho de que quienes aprueben la labor del presidente Morales muestren un mayor apoyo al sistema político refuerza lo observado en el caso venezolano: entre los seguidores del gobierno, el apoyo político será más alto, que entre sus opositores.

Finalmente, entre el 2014 y el 2016 no se observan cambios significativos, pero se comprueba la tendencia observada años anteriores: la aprobación del presidente Morales posa un efecto positivo sobre el soporte al sistema político. De esta forma, finalmente es explicable el hecho de que desde el 2006 Bolivia haya mejorado notablemente su indicador de apoyo al sistema político: la presencia en la presidencia de un personaje muy popular y con una favorabilidad muy alta incidió positivamente en este índice. Así, aunque esta variable pretende medir un apoyo abstracto al sistema democrático, al menos en el caso boliviano, termina siendo influenciada por la coyuntura política y las afinidades políticas. 
Figura 5. Nivel de apoyo al sistema político en Venezuela, Bolivia y Ecuador (1998-2016)

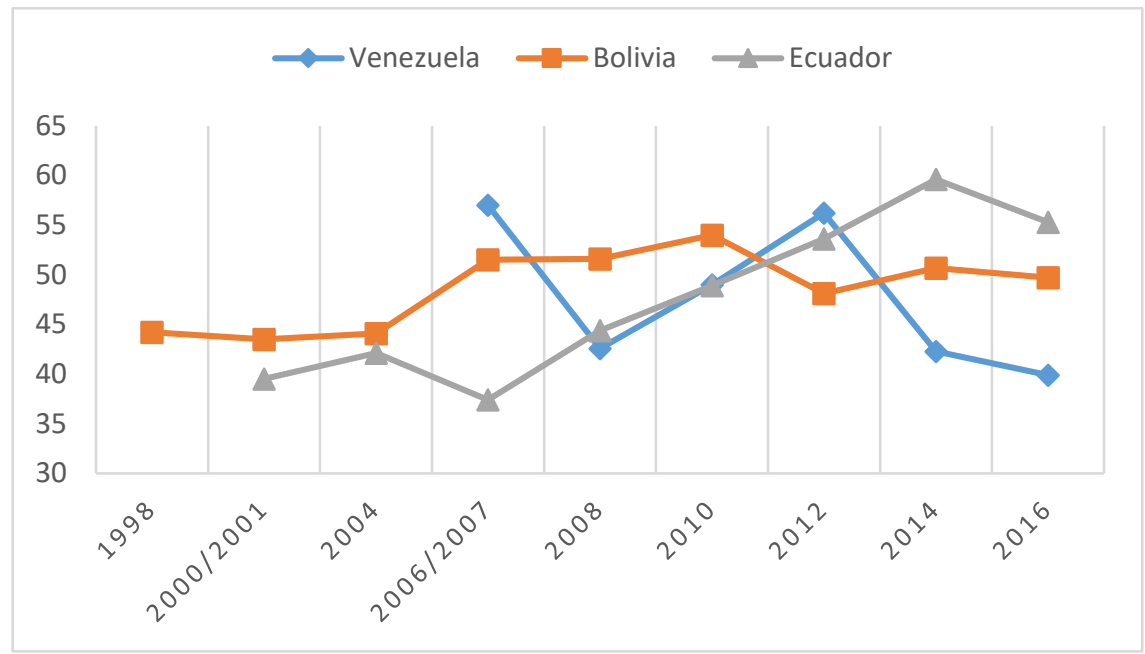

Fuente: Elaboración propia a partir de los datos del Barómetro de las Américas por el Proyecto de Opinión Pública de América Latina (LAPOP), www.LapopSurveys.org

Por su parte, en Ecuador, entre el 2001 y el 2006, el apoyo al sistema se mantuvo en niveles bastante bajos, tanto que en el 2006 Ecuador estuvo de último entre 22 países medidos en la región. Empero, en el 2008 hubo un aumento de 7 puntos en la medición, justo un año después de la llegada de Rafael Correa a la presidencia. Hasta el 2014, esta tendencia al aumento en el indicador de apoyo al sistema se consolidó y logró superar con creces la barrera de 50 puntos que no había sido alcanzada por el país nunca antes en la medición.

En el 2010, Ecuador, aunque se mantenía comparativamente bajo en esta sección, logró ganar posiciones y ubicarse 19 de 25 países medidos. Asimismo, tal como en el caso boliviano, el componente que más daño le hacía al indicador era el referente a las cortes y los tribunales de justicia del país. Dos años después, Ecuador mantuvo la tendencia al crecimiento y, por primera vez en la historia de la medición, logró puntuar más de 50 en la sección de apoyo al sistema político. Esta mejora la permitió pasar a ocupar los lugares medios en la tabla de comparación regional y, en el 2014, el país volvió a tener un aumento importante al ganar seis puntos en esta sección. Asimismo, tal como ha sido posible establecer para los casos venezolano y boliviano, en Ecuador el índice de apoyo al sistema está fuerte y positivamente afectado por la aprobación del trabajo del presidente de turno.

\section{LEGITIMIDAD DEMOCRÁTICA EN VENEZUELA, BOLIVIA Y ECUADOR: TOLERANCIA POLÍTICA}

La tolerancia política, a diferencia del apoyo al sistema, no presenta tendencias al aumento con la llegada de políticos populistas. En Venezuela, por ejemplo, si bien siempre hubo niveles inusualmente altos, al comparar la asociación partidista de los encuestados con sus respuestas, la puntuación promedio de quienes se identificaron como opositores del presidente Chávez fue de 77,3 puntos, mientras que la puntuación 
promedio de quienes se consideraron chavistas fue de 66,2 puntos. A pesar de que la puntuación de estos últimos no es baja, sí muestra un patrón interesante en las actitudes democráticas de los venezolanos: la filiación partidista determina, en cierta medida, las orientaciones hacia el sistema político (de forma positiva) y la tolerancia política (de forma negativa). Apoyar al presidente de turno, entonces, tiende a coincidir con tolerar menos a la oposición.

Según Hawkins, Patch y Anguiano (2008), una hipótesis explicativa puede ser que las duras experiencias durante los 9 años de consolidación del gobierno de Chávez pueden haber producido una "mayor apreciación por las normas pluralistas de tolerancia entre los grupos venezolanos" (p. 49). No obstante, al ser la primera medición del Barómetro de las Américas en Venezuela, no se podría comprobar que la oposición haya aumentado radicalmente sus niveles de tolerancia, o que el oficialismo los haya disminuido, durante la presidencia de Chávez.

Bolivia no evidenció aumentos radicales con la llegada de Evo Morales al poder. A pesar de que la tendencia a puntuar bajo no se inicia con Morales, sí sucedió después de su llegada que aquellos que aprobaban su gestión disminuyeron su nivel de tolerancia y quienes se encontraban en oposición la aumentaron. Estos cambios en función del grupo de población al que se pertenece no estaban presentes antes del 2006 y sugieren, tal como en el caso venezolano, que la aprobación de un presidente con discurso populista puede tener una relación negativa con la tolerancia política (Moreno et al., 2008).

Para el 2010, a pesar de que hubo un aumento considerable del nivel de tolerancia política en el país, la puntuación de Bolivia estuvo apenas por encima de El Salvador y se evidenció nuevamente la relación negativa entre la aprobación del trabajo del presidente y la tolerancia política, así como una curiosa relación geográfica: los habitantes de Pando y Chuquisaca (tradicionalmente en oposición al presidente Morales) obtuvieron resultados más altos que el resto del país en tolerancia política.

La relación entre el trabajo del presidente Morales y las actitudes de los ciudadanos debe ser tenida en cuenta debido a que "este factor tiene mucha fuerza y resulta determinante en muchas de las relaciones, decisiones y posiciones que los ciudadanos asumen en el espacio público" (Moreno et al., 2010, p. 152). De hecho, el nivel más bajo de tolerancia política en Bolivia tuvo lugar en el 2014, muchos años después de consolidado el proyecto político del MAS y luego de casi un lustro de tendencia a la baja en este indicador. De esta forma, mientras la aprobación del trabajo del presidente posa un efecto positivo en el apoyo al sistema político, aquellos ciudadanos que mostraron complacencia frente al ejecutivo se mostraron más intolerantes que quienes estaban en oposición. 
Figura 6. Nivel de tolerancia política en Venezuela, Bolivia y Ecuador (1998-2016)

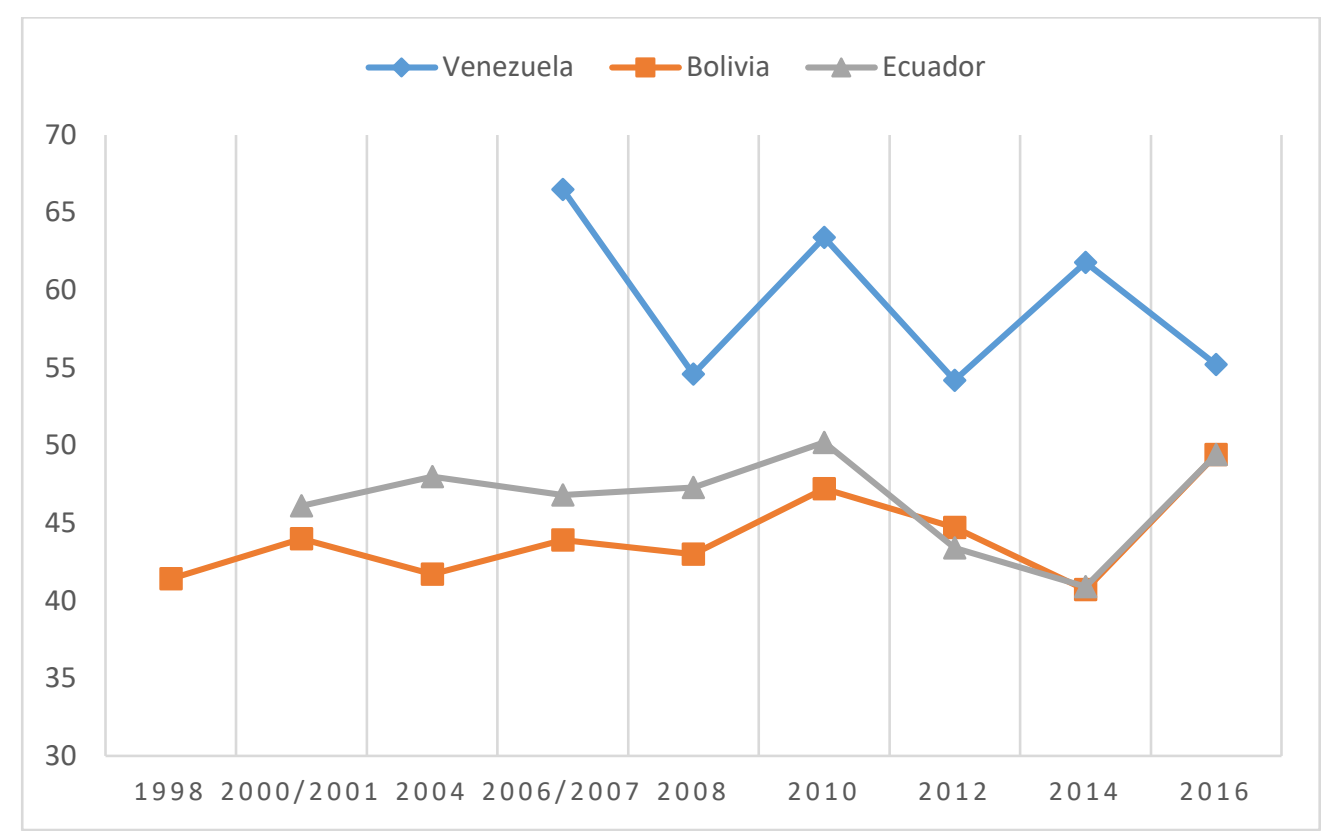

Fuente: Elaboración propia a partir de los datos del Barómetro de las Américas por el Proyecto de Opinión Pública de América Latina (LAPOP), www.LapopSurveys.org

En cuanto a Ecuador, igual que en el caso boliviano, este país no sufrió alteraciones importantes en este indicador con la llegada de Rafael Correa a la presidencia hasta el 2010, cuando luego de haber ganado cerca de 3 puntos, disminuyó radicalmente hasta perder cerca de 7 puntos en 4 años de medición. Aun así, en el 2016 hubo un aumento estadísticamente significativo que posicionó mejor al país, pero no fue suficiente para romper la barrera de los 50 puntos. De esta forma, desde el 2010, la tolerancia política en Ecuador siguió la tendencia opuesta a la de apoyo al sistema político: en el 2010, ambos índices se acercaron y, a partir de aquí, el apoyo al sistema creció hasta alcanzar su mejor posición en el 2014, mientras la tolerancia política disminuyó abruptamente hasta alcanzar su peor nivel en el país en este mismo año. Además, entre el 2014 y el 2016 la tolerancia volvió a ganar posiciones, pero el apoyo al sistema político disminuyó.

Si se observa particularmente la pregunta de si se debe garantizar el derecho al voto para quienes hablan mal del gobierno, desde la llegada de Correa, solo en el 2010 esta superó los niveles previos al 2006 y en el 2014 alcanzó su punto más bajo con solo un $44,9 \%$ de las personas respondiendo afirmativamente. Algo similar sucede con la garantía del derecho a postularse a cargos de gobierno para opositores: en el 2014 solo un $33,4 \%$ de los ecuatorianos consideraban que así debería ser y, desde que Correa llegó a la presidencia, los niveles tienden a ser ampliamente más bajos. 


\section{Perfiles actitudinales en Venezuela, Bolivia y ECUAdor: la llegada de LA ESTABILIDAD AUTORITARIA}

Dados estos niveles de apoyo al sistema y tolerancia política, ahora se busca identificar qué tipo de perfiles actitudinales existían antes de la llegada de estos políticos a la presidencia de Venezuela, Bolivia y Ecuador y cómo estas tendencias se modificaron hasta el 2016. Con respecto al perfil actitudinal "deseable" (alto apoyo al sistema y alta tolerancia política), puede observarse que, aunque en Venezuela este ha disminuido de forma considerable entre el 2010 y el 2016, en Bolivia y Ecuador ha tenido ligeros aumentos desde la llegada de Morales y Correa. En Bolivia, por ejemplo, en el 2016 el $24 \%$ de los entrevistados evidenciaban este perfil. No obstante, apenas un año antes esta cifra era apenas la mitad, por lo que se estaba más cerca de los niveles de 1998 que en cualquier otro momento. En Ecuador esa tendencia al aumento ha sido más sostenida y en el 2016 alcanzó a un $28 \%$ de la población, lo cual resultaba la cifra más alta hasta ese año.

Figura 7. Perfiles actitudinales tendientes a la democracia estable en Venezuela, Bolivia y Ecuador (1998-2016)

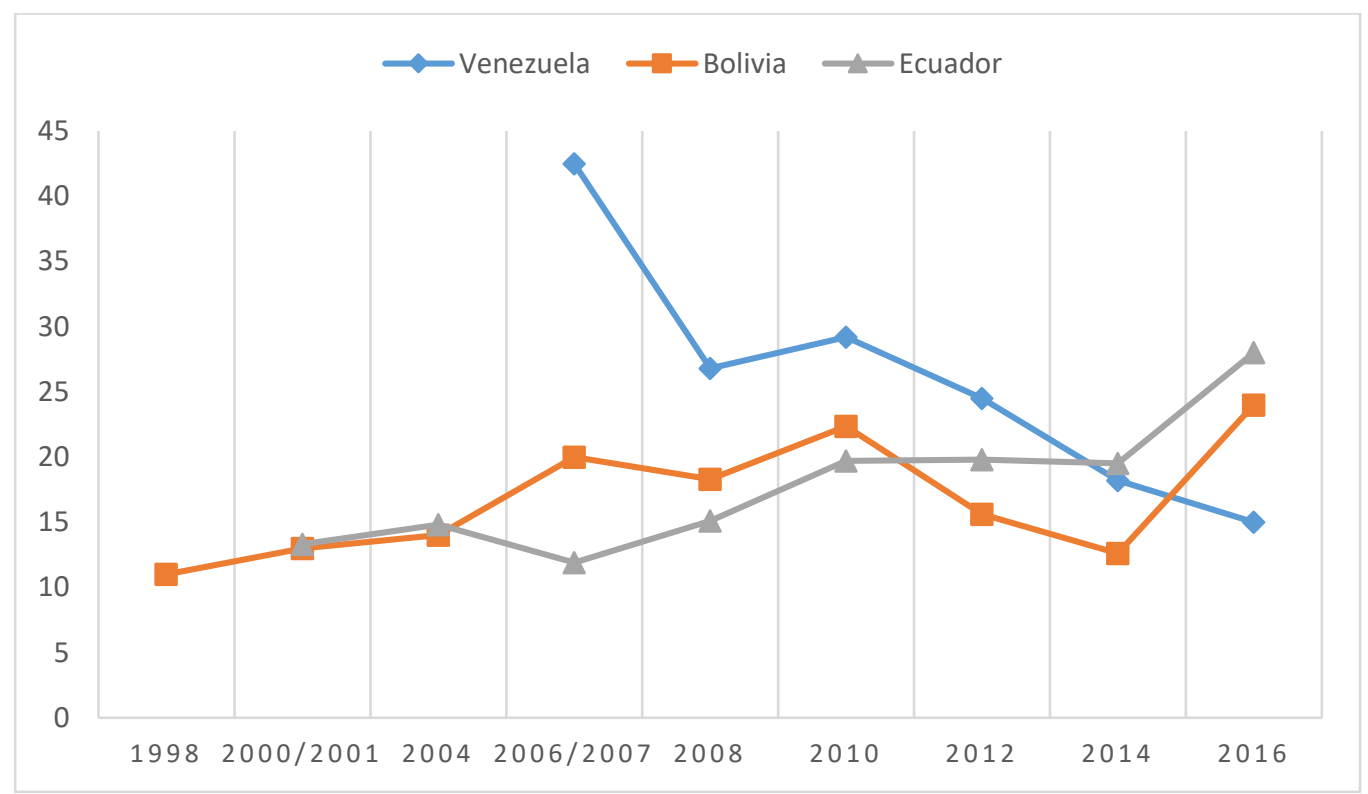

Fuente: Elaboración propia a partir de los datos del Barómetro de las Américas por el Proyecto de Opinión Pública de América Latina (LAPOP), www.LapopSurveys.org

Ahora, con respecto al perfil actitudinal tendiente a la democracia inestable (alta tolerancia política, pero bajo apoyo al sistema), es posible evidenciar que solo en Venezuela este ha tenido aumentos significativos. En este país, los resultados del 2014 llegaron a estar prácticamente dos veces por encima de los alcanzados en el 2006 (de 26,6\% a 43,8\%). Es decir, casi la mitad de los venezolanos se encontraban allí. En Bolivia, desde la llegada de Evo Morales este perfil actitudinal ha estado por debajo de los registrados previamente, lo que coincide con la hipótesis de que la presencia de este tipo de políticos produce un aumento del apoyo al sistema político, mientras pueden disminuir o no afectar la tolerancia política. En Ecuador, también, la tendencia es a la baja y, de 
hecho, en el 2014, apenas el 7,7\% de los ecuatorianos se encontraban registrados en este perfil actitudinal.

Figura 8. Perfiles actitudinales tendientes a la democracia inestable en Venezuela, Bolivia y Ecuador (1998-2016)

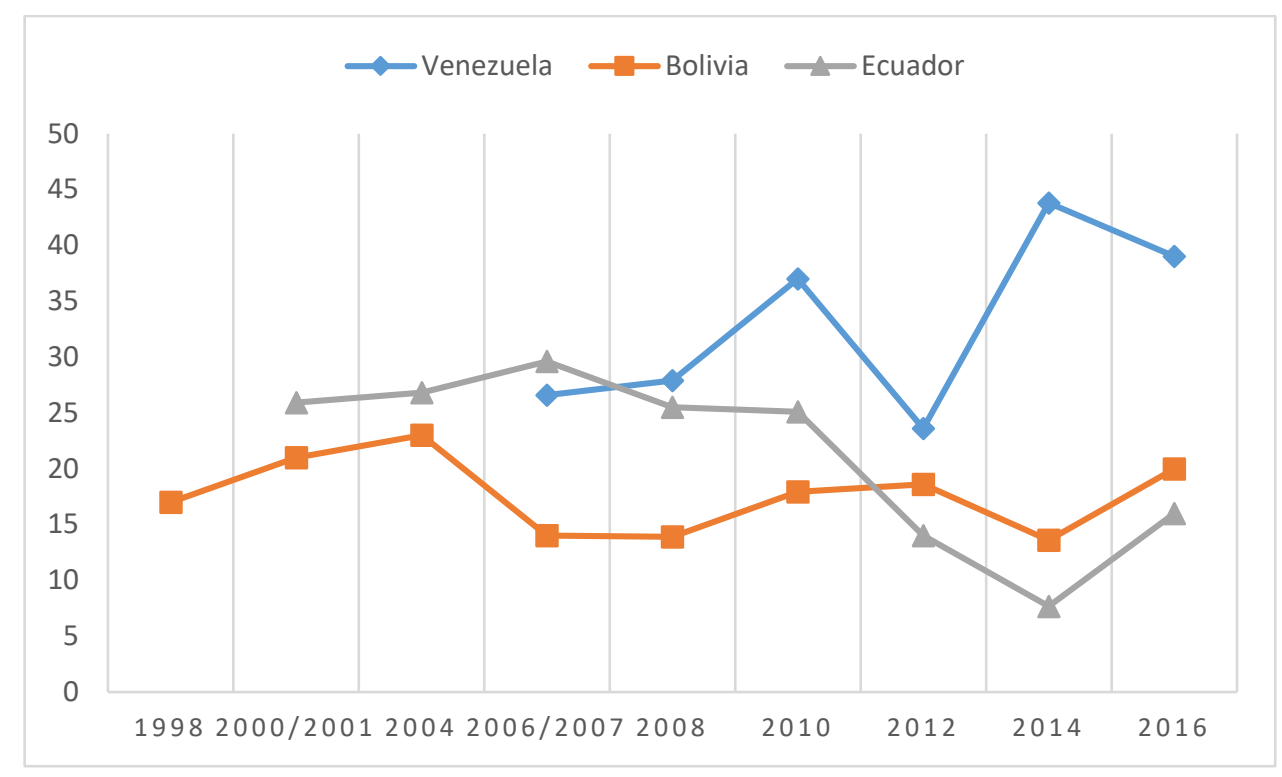

Fuente: Elaboración propia a partir de los datos del Barómetro de las Américas por el Proyecto de Opinión Pública de América Latina (LAPOP), www.LapopSurveys.org

$\mathrm{Al}$ analizar a los ciudadanos con perfiles actitudinales tendientes a la estabilidad autoritaria (alto apoyo al sistema y baja tolerancia política) aparece una tendencia mucho más marcada: mientras en Venezuela los niveles permanecen estables durante los años de las encuestas, en Bolivia y Ecuador hay escarpados aumentos desde que llegan al poder Evo Morales y Rafael Correa, respectivamente. En el primero, el año de la elección de Morales este perfil representó a cerca del 34\% de los bolivianos (el más alto entre los cuatro) y alcanzó sus niveles más altos entre el 2008 y el 2014. Aunque para el 2016 hubo una reducción significativa, sigue representando a cerca de un $25 \%$ de los encuestados.

En Ecuador, a pesar de que el porcentaje de ecuatorianos con perfiles actitudinales tendientes a la democracia estable ha aumentado de manera importante entre el $2001 \mathrm{y} \mathrm{el}$ 2016 (de 13,3\% a 24\%), el porcentaje de ciudadanos que poseen un perfil actitudinal tendiente a la estabilidad autoritaria aumentó en una proporción mucho mayor (de 15,5\% a 32\%) en el mismo periodo. Este perfil creció de manera mucho más pronunciada, sobre todo, entre el 2010 y el 2014. Este último año, casi la mitad de los ecuatorianos estaban alineados con la estabilidad autoritaria $(44,7 \%)$. Finalmente, aunque la disposición a la estabilidad autoritaria disminuyó de forma importante en el 2016, esta es aún $8 \%$ más alta que la democracia estable. 
Figura 9. Perfiles actitudinales tendientes a la estabilidad autoritaria en Venezuela, Bolivia y Ecuador (1998-2016)

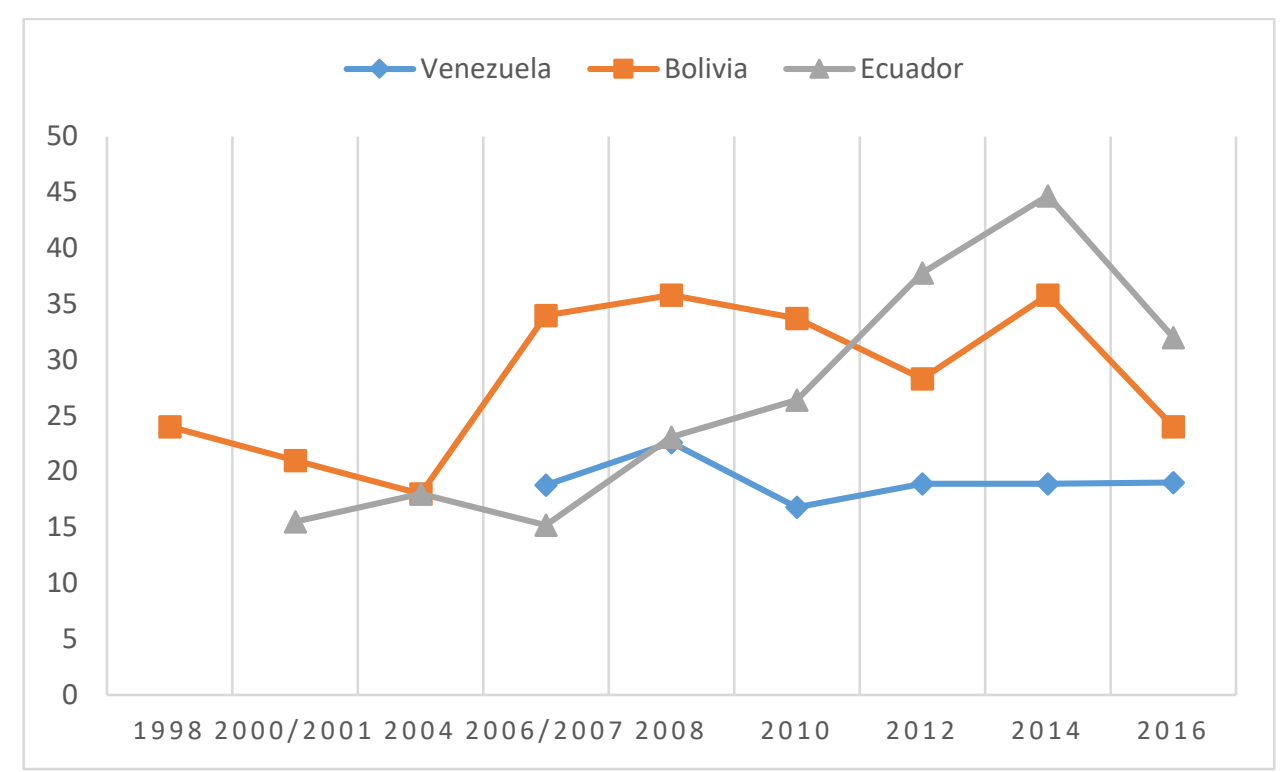

Fuente: Elaboración propia a partir de los datos del Barómetro de las Américas por el Proyecto de Opinión Pública de América Latina (LAPOP), www.LapopSurveys.org

Por último, el perfil actitudinal tendiente a la democracia en riesgo (bajo apoyo al sistema y baja tolerancia política) ha tenido también comportamientos diferenciados en Venezuela, Bolivia y Ecuador. Mientras en el primero hubo un aumento de más del doble entre el 2006 y el 2016 (de 12,1\% a 28\%), en Bolivia ha habido una reducción considerable desde la llegada de Evo Morales al poder. Los tres años de medición anteriores casi la mitad de los bolivianos se encontraban allí, mientras que en el 2016 estos solo representaban al $32 \%$ de la población. Si bien este es un porcentaje considerablemente alto ( $\mathrm{si}$ se tiene en cuenta que apenas el $24 \%$ tienen perfiles actitudinales tendientes a la democracia estable), sí permite observar que hubo un tránsito en las orientaciones democráticas de los ciudadanos. En Ecuador pudo observarse una reducción mucho más significativa: de mantener niveles por encima del $40 \%$ de la población, en el 2016 el país llegó a tener en esta categoría solo al 28\% de los ecuatorianos. De hecho, como puede observarse en la figura 9, esta reducción ha sido sostenida a lo largo del tiempo. 
Figura 10. Perfiles actitudinales tendientes a la democracia en riesgo en Venezuela, Bolivia y Ecuador (1998-2016)

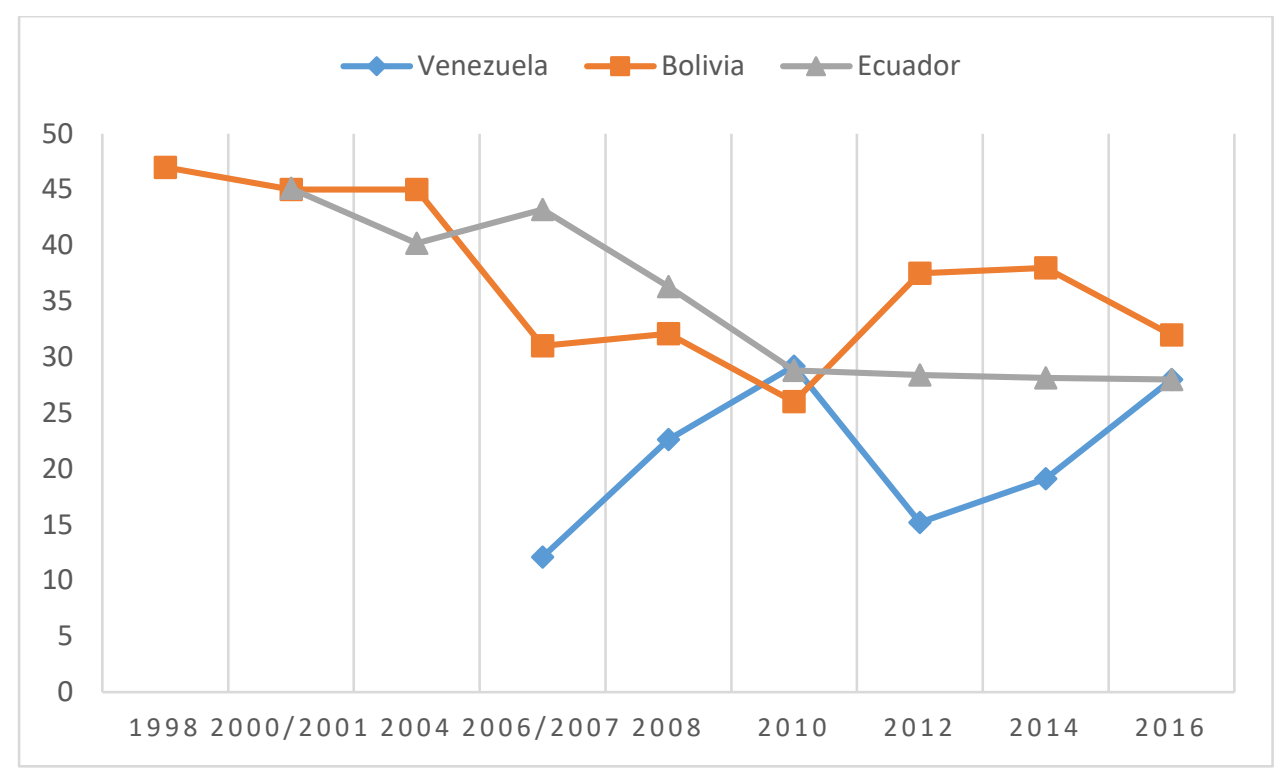

Fuente: Elaboración propia a partir de los datos del Barómetro de las Américas por el Proyecto de Opinión Pública de América Latina (LAPOP), www.LapopSurveys.org

\section{Populismos latinoamericanos: ¿DemocraCias EN RIESGo o AUTORITARISMOS ESTABLES?}

Los políticos populistas tienden a definir a la sociedad de forma dicotómica (evidencian la existencia de una "élite corrupta" y un "pueblo puro"), movilizan a las masas a partir de una promesa emancipatoria, suelen desdeñar públicamente el establecimiento político existente aludiendo a su inutilidad y dominio por parte de una élite corrupta, aseguran la necesidad de re-institucionalizar el orden existente y establecen una fuerte relación personalista entre ellos y sus seguidores. Todos los líderes analizados anteriormente (Hugo Chávez, Rafael Correa y Evo Morales) manifestaron, previo a su llegada al poder, este desdeño a las instituciones políticas y luego hicieron uso de esta promesa para construir una importante base de apoyo político.

Los tres, asimismo, lograron hacer triunfar el discurso de re-institucionalización del orden existente y sus esfuerzos en aras de lograr una constituyente que modificara las reglas de juego aludiendo a su inutilidad y dominio por parte de una élite corrupta. De hecho, este discurso emancipador es el que logra la movilización de masas y les permite alcanzar la victoria en su camino a la presidencia, las reelecciones y los distintos referendos a los que se sometieron, la mayoría con amplios márgenes de diferencia sobre sus opositores. Finalmente, la relación personalista entre el líder y los seguidores es evidenciable en los tres casos: por su parte, la muerte de Hugo Chávez Frías conmocionó al establecimiento político venezolano y su intento de mantener su legado a través de Nicolás Maduro fue infructuoso y profundizó las divisiones en la sociedad venezolana. Evo Morales permaneció en el poder 14 años y, de no ser por la crisis política que se gestó luego de las elecciones del 2019, habría estado allí hasta el 2024 sobre la excusa de que 
no hay nadie más capaz de mantener vigente su proyecto de reivindicación política del pueblo. Y, en el caso ecuatoriano, a pesar de que Rafael Correa decidió hacerse un lado y encargar a Lenin Moreno la continuación de su Revolución Ciudadana, al ver que sin su influencia el proyecto político declinaba y se esfumaba, decidió volver a hacer política, solo que los ecuatorianos impidieron su retorno a través de un referendo.

Esta rápida comprobación de los elementos populistas en los gobiernos de Chávez, Correa y Morales se hace en aras de no perder de vista que, más allá de establecer si en estos países hubo o no autoritarismo, este trabajo se plantea la importancia del discurso populista y su consolidación a fin de entender los cambios en la legitimidad democrática. Es por esto que, aunque haya una disminución de la calidad institucional de la democracia (evidenciada en la variación del Índice de Desarrollo Democrático), el apoyo al sistema político no disminuye y, por el contrario, aumenta con frecuencia. Este aumento en el apoyo al sistema político, paradójicamente, no se ve reflejado en el índice de tolerancia política, en el que hay una reducción significativa o inestabilidad en los países medidos.

Este comportamiento opuesto de los índices de apoyo al sistema político y tolerancia política puede explicar la razón por la cual la estabilidad autoritaria ha logrado ganar tanto lugar en Bolivia y en Ecuador, por lo que superó en todos los años a la categoría de democracia estable. Empero, en Venezuela la estabilidad autoritaria nunca ha sido demasiado fuerte y, por el contrario, es la democracia inestable la que desde el 2008 supera la categoría de democracia estable. Esto se explica en el hecho de que el apoyo al sistema político, en lugar de crecer, ha disminuido de niveles inusualmente altos en el 2007, a uno de los más bajos de la región en el 2016, mientras la tolerancia política en el país siempre ha mantenido niveles altos. Este comportamiento puede depender de los amplios niveles de persecución a la oposición política, sin parangón en los países estudiados, que terminan produciendo un mayor nivel de tolerancia política entre la oposición, al tiempo que desacreditan el sistema político golpeado, además, por una fuerte crisis económica.

De esta forma, la llegada de gobiernos populistas a Bolivia y Ecuador y la restructuración de las reglas de juego sí produjo mayor estabilidad democrática, pero no logró disipar la fragilidad del sistema político entre los ciudadanos, que pasaron de ostentar un perfil actitudinal conducente a una democracia en riesgo, a ubicarse con frecuencia en un perfil que propicia una estabilidad autoritaria. Dicho de otra forma, si bien en cuanto a legitimidad política estos países hicieron una transición desde democracias en riesgo, no es cierto que hayan logrado llegar hasta el objetivo de una democracia estable y todo parece indicar que se estancaron en una estabilidad autoritaria que propicia el desmantelamiento de las instituciones democráticas en aras de que estos líderes se perpetúen en el poder y/o persigan a su oposición política a fin de reconfigurar el escenario político, judicial y electoral a su favor.

El caso venezolano, lastimosamente, no permite un análisis a largo plazo debido a que las mediciones del Barómetro de las Américas apenas comenzaron en el 2007, año en el que el chavismo ya se había consolidado como única fuerza política en el país con opciones reales de poder. No obstante, es claro que progresivamente el país fue 
transitando de tener una población mayoritariamente ubicada en el perfil de democracia estable a una población que valora mucho menos al sistema político existente, al tiempo que le otorga alta importancia a la tolerancia política. Este contexto produjo una mayoría de ciudadanos con un perfil actitudinal tendiente a la inestabilidad democrática, pero debe hacerse claridad en el hecho de que Venezuela ha enfrentado situaciones que ni en Ecuador ni en Bolivia han sido presenciadas: la muerte del autor y consumador del proyecto populista y la profundización de una fuerte crisis económica que afecta indiscutiblemente las orientaciones políticas de los ciudadanos.

Es necesario reconocer dos limitaciones presentes en este estudio: en el caso venezolano hay un potencial problema de endogeneidad al no poder contrastar los resultados obtenidos con las orientaciones democráticas previas a la llegada al poder de Hugo Chávez. Es decir, no se puede saber si la sociedad presentaba niveles tan altos de tolerancia política y apoyo al sistema político por la influencia de este líder o por otras condiciones sociales. Aun así, plantear este tipo de discusiones puede ser útil para abrir espacios a nuevas preguntas de investigación relacionadas con brechas al interior de estas sociedades. Por ejemplo, ¿cómo se han comportado estos mismos indicadores entre quienes apoyaban a los gobiernos y quienes no? ¿es posible demostrar esa relación positiva entre apoyo al sistema político y apoyo al ejecutivo y esa misma relación negativa para el caso de la tolerancia política a lo largo del tiempo? ¿esas tendencias seguidas por los tres países difieren radicalmente con otros países de América Latina? ¿se puede hacer las mismas inferencias para políticos que, aunque no se ubican consistentemente dentro de la categoría de populista, sí manifiestan altos rasgos de personalismo?

En segundo lugar, aunque se han presentado algunas hipótesis con respecto a esto, sigue sin resultar claro por qué la trayectoria de las orientaciones democráticas en Venezuela siguió un curso tan diferente al de Bolivia y Ecuador. En teoría, la presencia de un político populista, debido a su discurso, debería alterar negativamente los niveles de tolerancia política y producir mayor apoyo al sistema. No obstante, en Venezuela sucedió exactamente lo contrario: el primer indicador se mantuvo considerablemente alto con respecto al resto de países de la región y el segundo indicador disminuyó de forma progresiva. Si bien esto podría estar relacionado con la muerte de Chávez y la crisis económica, social y política del país, es necesario mencionar que desde antes había signos de este comportamiento, por lo que resulta un tema de investigación que fue abordado solo de forma parcial en la investigación y que presenta oportunidades para próximos investigadores.

\section{REFERENCIAS}

Akkerman, A., Mudde, C., y Zaslove, A. (2013). How Populist Are the People? Measuring Populist Attitudes in Voters. Comparative Political Studies, 47(9), pp. 1324-1353. doi:10.1177/0010414013512600

Almonte, M., y Crespo, A. (2008). El Populismo en América Latina: ¿pasado o presente? Madrid: Fundación Iberoamérica Europa.

Badillo Sarmiento, R. (2018). Populismo y legitimidad democrática: ¿de democracias en riesgo a la estabilidad autoritaria? [Trabajo de grado]. Bogotá: Observatorio de la Democracia (Universidad de Los Andes). Disponible en https://bit.ly/3cJ0xRI 
Barros, S. (2014). Momentums, demos y baremos. Lo popular en los análisis del populismo latinoamericano. Revista de Reflexión y Análisis Político, 19(2), pp. 315-344.

Basabe, S., y Martínez, J. (2014). Ecuador: Cada vez menos democracia, cada vez más autoritarismo... con elecciones. Revista de Ciencia Política, 34(1), pp. 145-170. DOI: $10.4067 /$ S0718-090X2014000100007.

Booth, J., y Seligson, M. (2009). The legitimacy puzzle in Latin America. Cambridge: Cambridge University Press.

Caiani, M., y Graziano, P. (2019) Understanding varieties of populism in times of crises. West European Politics, 42(6), pp. 1141-1158, DOI: 10.1080/01402382.2019.1598062

Cammack, P. (2000). The resurgence of populism in Latin America. Bulletin of Latin American Research, 19(2), pp. 149-161.

Carlin, R., Love, G. y Singer, M. (2015). Una década de legitimidad democrática en las Américas. En: J. Carrión, P. Zárate y E. Zechmeister (eds.), Cultura política de la democracia en Perú y en las Américas, 2014: Gobernabilidad democrática a través de 10 años del Barómetro de las Américas (pp. 93-124). Lima: Instituto de Estudios Peruanos.

Carlin, R., y Singer, M. (2011). Support for Polyarchy in the Americas. Comparative Political Studies, 44(11), pp. 1500-1526. https://doi.org/10.1177/0010414011407471

Castanho Silva, B., Jungkunz, S., Helbling, M., y Littvay, L. (2019). An Empirical Comparison of Seven Populist Attitudes Scales. Political Research Quarterly, 00(0), pp. 1-16. https://doi.org/10.1177/1065912919833176

Ciudadanía y LAPOP. (2012). Cultura política de la democracia en Bolivia, 2012. Cochabamba: Ciudadanía, Comunidad de Estudios Sociales y Acción Pública.

Ciudadanía y LAPOP. (2014). Cultura política de la democracia en Bolivia, 2014: Hacia una democracia de ciudadanos. Cochabamba: Ciudadanía, Comunidad de Estudios Sociales y Acción Pública.

Cuñarro, E. y Cuñarro, L. (2017). Democracia y populismo en América Latina. Algunas notas sobre Uruguay y Venezuela. Justicia, 31(1), pp. 46-64. http://dx.doi.org/ 10.17081/just.22.31.2598

Dahl, R. (1989). Democracy and Its Critics. New Haven: Yale University Press.

De la Torre, C. (2007). The Resurgence of Radical Populism. Constellations, 14(3), pp.384-397. DOI: 10.1111/j.1467-8675.2007.00453.x

De la Torre, C. (2010). El gobierno de Rafael Correa: posneoliberalismo, confrontación con los movimientos sociales y democracia plebiscitaria. Revista Temas Y Debates, 20(14), pp. 157-172.

De Vreese, C. H., Esser, F., Aalberg, T., Reinemann, C., y Stanyer, J. (2018). Populism as an expression of political communication content and style: A new perspective. The international journal of press/politics, 23(4), pp. 423-438. DOI: $10.1177 / 1940161218790035$

Diamond, L. (1999). Developing Democracy: Toward Consolidation. Baltimore: Johns Hopkins University Press.

Dirmose, D. (2005). Democracia sin demócratas. Nueva Sociedad, 197(1), pp. 28-41.

Easton, D. (1975). A Re-Assessment of the Concept of Political Support. British Journal of Political Science, 5(4), 435-457. DOI: https://doi.org/10.1017/S0007123400008309 
Fermandois, J. (2015). Entusiasmo y desconfianza. Populismo y relaciones internacionales en el caso Perón-Ibáñez, 1953-1955. Ayer: Revista de Historia Contemporánea, 98(2), pp. 187-211.

Finkel, S. (2002). Civic education and the mobilization of political participation in developing democracies. Journal of Politics, 64(4), pp. 994-1020. DOI: https://doi.org/10.1111/1468-2508.00160

Finkel, S., Sigelman, L., y Humphries, S. (1999). Democratic values and political tolerance. En J.P. Robinson, P.R. Shaver, y L.S. Wrightsman (Eds.), Measures of political attitudes (pp. 203-296). New York: Academic Press.

Franchini, M. (2007). Asamblea Constituyente en Bolivia: Génesis, evolución y conflicto en el cambio. Buenos Aires: Centro para la Apertura y el Desarrollo de América Latina.

Frei, R., y Kaltwasser, C. (2008). El populismo como experimento político: historia y teoría política de una ambivalencia. Revista de sociología, 22(1), pp. 117-140. DOI: 10.5354/0719-529X.2008.14485

Fuchs, D., y Roller, D. (2006). Learned Democracy? Support for Democracy in Central and Eastern Europe. International Journal of Sociology, 36(3), pp. 70-96. https://doi.org/10.2753/IJS0020-7659360303

Fuks, M., Avila, G., Quaresma, G., y Felizardo, F. (2016). Qualificando a adesão à democracia: quão democráticos são os democratas brasileiros?. Revista Brasileira de Ciência Política, 19(1), PP. 199-219. DOI: http://dx.doi.org/10.1590/0103335220161908

Fundación Konrad Adenauer y Polilat (2009). Índice de desarrollo democrático de América Latina IDD-LAT 2009. Buenos Aires: Fundación Konrad Adenauer.

Gagnon, J., Beausoleil, E., Son, K., Arguelles, C., Chalaye, P., y Johnston, C. (2018). What is populism? Who is the populist? A state of the field review (2008-2018). Democratic Theory, 5(2), pp. 11- 26.

García, J. (2012). Latinoamérica: entre la democracia y el autoritarismo. Estudios Políticos, 41(1), pp. 15-35.

García, M., Rodríguez, J., Seligson, M., y Zechmeister, E. (2015). Cultura política de la democracia en Colombia, 2014 Dilemas de la democracia y desconfianza institucional en el marco del proceso de paz. Bogotá: Observatorio de la Democracia de la Universidad de los Andes.

Geurkink, B., Zaslove, A., Sluiter, R., y Jacobs, K. (2019). Populist Attitudes, Political Trust, and External Political Efficacy: Old Wine in New Bottles? Political Studies, 00(0), pp. 1-21. https://doi.org/10.1177/0032321719842768

Gibson, J. (1996). The paradoxes of political tolerance in processes of democratization. Politikon: South African Journal of Political Studies, 23(2), pp. 5-21. DOI: https://doi.org/10.1080/02589349608705033

Gibson, J. (2011). Political Intolerance in the Context of Democratic Theory. En R. Goodin (ed.), The Oxford Handbook of Political Science (pp. 323-341). Nueva York: Oxford University Press.

Hawkins, K., Patch, J., y Anguiano, A. (2008). Political Culture of Democracy in Venezuela: 2007. Vanderbilt: Vanderbilt University.

IDD-Mex. (2018). Índice de Desarrollo Democrático de México. Ciudad de México: Fundación Konrad Adenauer, Politat, INE, USEM, Cepos y Colmex.

Laclau, E. (1996). Emancipación y Diferencia. Buenos Aires: Ariel.

Laclau, E. (2005a). La razón populista. Buenos Aires: Fondo de Cultura Económica.

Laclau, E. (2005b). Populism: What's in a Name. En F. Panizza (ed.), Populism and the Mirror of Democracy (pp. 32-49). Londres: Verso. 
Laclau, E. (2012). Antagonismo, subjetividad y política. Debates y Combates, 2(3), pp. 7-37.

Laclau, E., y Mouffe, C. (2015). Hegemonía y estrategia socialista. Hacia una radicalización de la democracia. Buenos Aires: Fondo de cultura económica.

Leone, J., y Calderón, J. (2004). Aventuras y desventuras del populismo latinoamericano. Revista de estudios políticos, (124), pp. 229-244.

Levitsky, S. y Roberts, K. (2011). Latin America's "Left Turn": A Framework for Analysis. En: S. Levitsky y K. Roberts (eds.), The Resurgence of the Latin American Left. Baltimore: Johns Hopkins University Press.

Levitsky, S., y Loxton, J. (2013). Populism and competitive authoritarianism in the Andes. Democratization, 20(1), pp. 107-136.DOI: https://doi.org/10.1080/13510347.2013.738864

Levitsky, S., y Way, L. (2010). Competitive authoritarianism: Hybrid regimes after the Cold War. Cambridge: Cambridge University Press.

Luna, G. (2014). Ecuador: economía y política de la revolución ciudadana, evaluación preliminar. Apuntes del CENES, 33(58), pp. 109-134.

Mair P. (2002). Populist Democracy vs Party Democracy. En Y. Mény, \& Y. Surel (eds), Democracies and the Populist Challenge (pp. 81-98). Londres: Palgrave Macmillan.

Mancini, Y. (2014). ¿Cómo conviven las tendencias autoritarias y democráticas en Venezuela y Bolivia? Análisis de los mandatos de Hugo Chávez (1999-2009) y Evo Morales (2005-2009). Carta Informativa De La Junta De Estudios Históricos De La Matanza, 36(1), pp. 1-25.

Márquez, T. (2014). Presidencialismo, autoritarismo y culto a la personalidad (Hugo Chávez y el ejercicio del poder). Revista Venezolana de Análisis de Coyuntura, 10(2), pp.57-77.

Moreno, D., Córdova, E., Schwarz, V., Seligson, M., Vargas, G., y Villarroel, M. (2008). Cultura política de la democracia en Bolivia, 2008. Cochabamba: Ciudadanía, Comunidad de Estudios Sociales y Acción Pública.

Moreno, D., Córdova, E., Schwarz, V., Vargas, G., y Villarroel, M. (2010). Cultura política de la democracia en Bolivia, 2010. Cochabamba: Ciudadanía, Comunidad de Estudios Sociales y Acción Pública.

Mouffe, C. (1999). El retorno de lo político: comunidad, ciudadanía, pluralismo, democracia radical. Barcelona: Paidós Iberica.

Mudde, C. (2004). The populist zeitgeist. Government and opposition, 39(4), pp. 541563. DOI: https://doi.org/10.1111/j.1477-7053.2004.00135.x

Mudde, C., y Rovira Kaltwasser, C. (2013). Exclusionary vs. Inclusionary Populism: Comparing Contemporary Europe and Latin America. Government and Opposition, 48(2), pp. 147-174. DOI:10.1017/gov.2012.11

Panizza, F. (2008). Fisuras entre populismo y democracia en América Latina. En C. de la Torre y E. Peruzzotti, El retorno del pueblo Populismo y nuevas democracias en América Latina (pp. 77-97). Quito: FLACSO.

Ponce, J. (2014). ¿Una revolución pacífica y armada? Cambio, conflicto, violencia social y política durante la revolución bolivariana de Venezuela, 1989-2006. Estudios Políticos, 46, pp. 33-54.

Reano, A. (2014). Populismo (en) democracia. Repensando los sentidos de la emancipación en el sur de América Latina. Colombia Internacional, 82, pp. 99128.

Retamozo, M. (2017). La teoría del populismo de Ernesto Laclau: una introducción. Estudios Políticos, 41(2), pp. 157-184. 
Ribeiro, E., y Borba, J. (2017). Tolerância Política no Brasil recente. Conferencia presentada en el Congreso $9^{\circ}$ Congreso Latinoamericano de Ciencia Política, Montevideo: Alacip. Disponible en: https://bit.ly/2PUdWwr

Roberts, K. (2007). Latin America's populist revival. SAIS Review of International Affairs, 27(1), pp. 3-15. DOI: 10.1353/sais.2007.0018

Savarino, Franco. (2006). Populismo: perspectivas europeas y latinoamericanas. Espiral, 13(37), pp. 77-94.

Schulz, A., Müller, P., Schemer, C., Wirz, D. S., Wettstein, M., y Wirth, W. (2017). Measuring Populist Attitudes on Three Dimensions. International Journal of Public Opinion Research, 30(2), pp. 316-326. doi:10.1093/ijpor/edw037

Segal, A. (2013). Totalitarismo, dictadura y autoritarismo: Definiciones y re-definiciones. Revista Gobierno Y Gestión Pública, 1(1), pp. 1-37.

Seligson, M., Cordova, A., Donoso, J., Moreno, D., Orcés, D., y Schwarz, V. (2007). Auditoría de la democracia: Informe Bolivia 2006. Vanderbilt: Vanderbilt University.

Taguieff, P. (1997). Le populisme et la science politique. Du mirage conceptuel aux vrais problèmes. Vingtième Siècle. Revue D'histoire, (56), 4-33. doi:10.2307/3770596

Tibocha, A., y Jaramillo Jassir, M. (2008). La Revolución Democrática de Rafael Correa. Análisis Político, 21(64), pp. 22-39.

Ulloa, C. (2013). El populismo en la democracia. Forum, Revista Departamento Ciencia Política, 4(1), pp. 83-94.

Wilde, M. (2017). Utopian disjunctures: Popular democracy and the communal state in urban Venezuela. Critique of Anthropology, 37(1), pp. 47-66. https://doi.org/10.1177/0308275X16671787

Wirth, W., Esser, F., Wettstein, M., Engesser, S., Wirz, D., Schulz, A. ... y Schemer, C. (2016). The appeal of populist ideas, strategies and styles: A theoretical model and research design for analyzing populist political communication. NCCR Democracy Working Paper series. 